\title{
Synthesis and Cytotoxic Distinction of Benzo[h]naphtho[1,2-b] $[1,6]$ Naphthyridine and its Isomeric Benzo[b]naphtho[1,2-h][1,6] Naphthyridines
}

Kolandaivel Prabha and K J Rajendra Prasad*

Department of Chemistry, Bharathiar University, Coimbatore, Tamil Nadu, India

\begin{abstract}
Benzo[ $h]$ naphtho[1,2- $b][1,6]$ naphthyridine and its isomeric benzo[ $b]$ naphtho[1,2- $h][1,6]$ naphthyridine with aliphatic, aromatic and hetero substitution were synthesized and screened for its antiproliferative activity against four human cancer cell lines. Among these, HeLa cells are more susceptible to compounds $3 \mathrm{a}, 3 \mathrm{~b}, 9 \mathrm{a}$ and $9 \mathrm{~b}$ with $\mathrm{IC}_{50}$ values of $3.62,1.05,6.21$ and $1.41 \mu \mathrm{M}$ respectively. Interestingly chloro substituted compound $9 \mathrm{~b}$ showed $\mathrm{IC}_{50}$ values of 5.93 , 7.01, and 6.81 $\mu \mathrm{M}$ against MCF7, K562 and Hep-G2 cancer cells, which is more active than the standard adriamycin. Furthermore chloro substituted compound 3b displayed good activity against MCF7 (IC $\left.{ }_{50} 6.63 \mu \mathrm{M}\right)$ and K562 (IC 50.23 $\mu \mathrm{M})$ cancer cell lines. This study also revealed that, benzo[ $h]$ naphtho[1,2-b][1,6] naphthyridine series were more active than its isomeric benzo[b]naphtho[1,2-h][1,6] naphthyridines.
\end{abstract}

Keywords: Cholro quinolines; Cytotoxicity; SAR studies; Positional isomers

\section{Introduction}

The need of exploring novel synthetic strategies to make new heterocycles is still expanding owing to meet the challenges in identifying new lead compounds for various therapeutic areas. It is also quite evident from literature that closely related isomers/heterocycles behave quite differently to the biological target [1]. For instance, it was demonstrated that 6-isomers of 5, 8-O dimethyl acylshikonin derivatives exhibit higher inhibitory effects on DNA topoisomerase-I and also had upper hand in vitro $\mathrm{IC}_{50}$ values against L1210 cell than its corresponding 2-isomer (Figure 1). This triggers further interest to study one of the potent isomers which lead to potential candidate both in vitro and in vivo studies using $\mathrm{KM}$ mice model [2,3]. When screened a small collection of tricyclic 4-(phenylamino)furo[2,3-b] quinolone and its positional isomer, 2-(furan-2-yl)-4-(phenylamino) quinolone against $60 \mathrm{NCI}$ cancer cells (Figure 1). Tzeng et al. found that one of the former isomer turns out to be more cytotoxic whereas its corresponding isomer is inactive [4]. A comparison of the biological activity of isomers with varying alkyl substitutions on the heterocyclic nitrogen of benzhydro[f]quinoline derivatives was made. The trans-isomer was effective rather than the cis-isomer in relaxing methacholine contracted guinea-pig trachea through a $\beta$-adrenergic mechanism since propranol blocked this response [5].

The continuous quest to develop nitrogen containing small molecules in the area of cancer is quite tremendous. Among them quinolones and naphthyridines were identified as one of the most promising scaffolds. As evident from the literature these compounds (EKB-569, HKI-272 and SNS-595) were in different phases of clinical trials [6]. Quinoline and its analogues were also known for its anti-tuberculosis $[7,8]$, antiproliferative $[9,10]$, anthelmintic [11], antibacterial [12], antiviral [13], Scr tyrosine kinase inhibitors [14], antioxidant activities [15] and metal chelating properties [16]. Various Naphthyridine derivatives exert their biological activity by inhibiting topoisomerase-I [17], Akt1 and Akt2 [18], HIV integrase [19,20], c-Met kinase inhibitors [21]. Certain naphthyridine derivatives also exhibit antitumour [22-24], anticonvulsive [25], $\mathrm{CB}_{2}$ selective agonist properties [26].

These interesting facts coupled with our current interest in unraveling the interesting anticancer properties of various nitrogen heterocycles prompted us to explore the biological activities of two positional isomers in greater detail. A general strategy to obtain both benzo napthonaphthyridines and its isomer was developed and their in vitro cytotoxicity we studied systematically and the results are presented in this manuscript.

\section{Experimental Protocols}

\section{General}

Melting points (m.p.) were determined on Mettler FP 51 apparatus (Mettler Instruments) and are uncorrected. They are expressed in degree centigrade $\left({ }^{\circ} \mathrm{C}\right)$. A Nicolet Avatar Model FT-IR spectrophotometer was used to record the IR spectrum $\left(4000-400 \mathrm{~cm}^{-1}\right) .{ }^{1} \mathrm{H}$ NMR and ${ }^{13} \mathrm{C}$ NMR spectra were recorded on Bruker AV $400\left[400 \mathrm{MHz}\left({ }^{1} \mathrm{H}\right)\right.$ and $100 \mathrm{MHz}$ $\left.\left({ }^{13} \mathrm{C}\right)\right]$ and AV $500\left[500 \mathrm{MHz}\left({ }^{1} \mathrm{H}\right)\right.$ and $\left.125 \mathrm{MHz}\left({ }^{13} \mathrm{C}\right)\right]$ spectrometer using tetramethylsilane (TMS) as an internal reference. The chemical shifts are expressed in parts per million (ppm). Mass spectra (MS) were recorded on Auto Spec EI+ Shimadzu QP 2010 PLUS GC-MS mass spectrometer. Microanalyses were performed on a Vario EL III model CHNS analyzer (Vario, Germany). The solvent and reagents used for the preparations were of reagent grade and were purified by standard methods; petroleum ether used was of boiling range $60-80^{\circ} \mathrm{C}$. Anhydrous sodium sulphate was used to dry the solution of organic extracts. Thin layer chromatography (TLC) was performed using glass plates coated with silica gel-G containing $13 \%$ calcium sulphate as binder. Ethyl acetate and petroleum ether were used as developing solvents. A chamber containing iodine vapour was used to locate the spots. Separation and purification of the crude products was carried out using chromatographic columns packed with activated silica gel (60-120 mesh). In the case of mixture of solvents used for elution, the ratio of the mixture is given in brackets.

*Corresponding author: K. J. Rajendra Prasad, Department of Chemistry, Bharathiar University, Coimbatore, Tamil Nadu, India, Tel: +919865972521; E-mail: prasad_125@yahoo.com

Received December 20, 2015; Accepted January 25, 2016; Published January 27,2016

Citation: Prabha K, Prasad KJR (2016) Synthesis and Cytotoxic Distinction of Benzo[ $h]$ naphtho[1,2-b][1,6] Naphthyridine and its Isomeric Benzo[b]naphtho[1,2- $h]$ $[1,6]$ Naphthyridines. Med chem 6: 062-071. doi:10.4172/2161-0444.1000326

Copyright: @ 2016 Prabha K, et al. This is an open-access article distributed under the terms of the Creative Commons Attribution License, which permits unrestricted use, distribution, and reproduction in any medium, provided the original author and source are credited. 
<smiles>[R]C(=O)OC(CC=C(C)C)c1cc(OC)c2c(c1OC)C(=O)C=CC2=O</smiles>

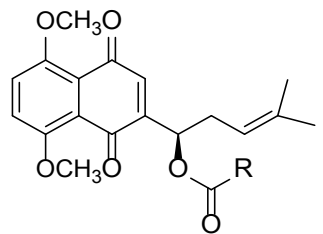

6-and 2-isomers of 5,8-O-dimethyl acylshikonin derivatives<smiles>c1ccc(Nc2c3ccccc3nc3occc23)cc1</smiles>

4-(phenylamino)furo[2,3-b]quinolone more $\mathrm{NCl}$ cancer cell line activity

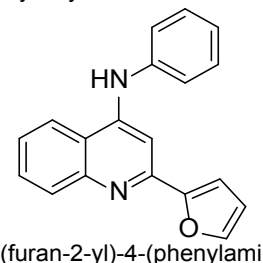

2-(furan-2-yl)-4-(phenylamino)quin
less $\mathrm{NCl}$ cancer cell line activity

Figure 1: Structure of some isomer compounds.

\section{Synthesis}

Preparation of hetero substituted benzo[h]naphtho[1,2-b] $[1,6]$ naphthyridine $(7,8$ and 9$)$, general procedure: 2 -Methyl- $N-(1-$ naphthyl)quinolin-4-amine $(3,0.002 \mathrm{~mol})$ and pyridine-3-carboxylic acid /thiophen-2-carboxylic acid/furan-2-carboxylic acid (0.0025 mol) were added to polyphosphoric acid $\left(6 \mathrm{~g}\right.$ of $\mathrm{P}_{2} \mathrm{O}_{5}$ in $3 \mathrm{~mL}$ of $\left.\mathrm{H}_{3} \mathrm{PO}_{4}\right)$ and heated at $110^{\circ} \mathrm{C}$ for 1 hour. The reaction was monitored by using TLC. After completion of the reaction, it was poured into ice water, neutralized with saturated sodium bicarbonate solution to remove excess of pyridine-3-carboxylic acid/thiophen-2-carboxylic acid/furan2-carboxylic acid, extracted with ethyl acetate, purified by column chromatography using silica gel to get 7-9 which was recrystallised using methanol.

2,6-Dimethyl-7-(pyridin-3'-yl)benzo[ $h]$ naphtho[ $1,2-b][1,6]$ naphthyridine (7a): Pale yellow solid; mp: $242-244^{\circ} \mathrm{C}$; Yield: (44\%); IR $\left(\mathrm{KBr}, \mathrm{cm}^{-1}\right) v_{\max }: 1634(\mathrm{C}=\mathrm{N}), 1598,1547 ;{ }^{1} \mathrm{H} \mathrm{NMR}\left(500 \mathrm{MHz}, \mathrm{CDCl}_{3}\right)$ $\delta_{\mathrm{H}}: 2.36\left(\mathrm{~s}, 3 \mathrm{H}, \mathrm{C}_{4}-\mathrm{CH}_{3}\right), 2.92\left(\mathrm{~s}, 3 \mathrm{H}, \mathrm{C}_{6}-\mathrm{CH}_{3}\right), 7.15\left(\mathrm{~d}, 1 \mathrm{H}, \mathrm{C}_{3}-\mathrm{H}, J=9.00\right.$ $\mathrm{Hz}), 7.28\left(\mathrm{t}, 1 \mathrm{H}, \mathrm{C}_{5}{ }^{\prime}-\mathrm{H}, J=8.50 \mathrm{~Hz}, J=5.00 \mathrm{~Hz}\right), 7.38-7.73\left(\mathrm{~m}, 4 \mathrm{H}, \mathrm{C}_{2}, \mathrm{C}_{12}\right.$, $\mathrm{C}_{9}$ and $\left.\mathrm{C}_{11}-\mathrm{H}\right), 7.84\left(\mathrm{dd}, 1 \mathrm{H}, \mathrm{C}_{4}^{\prime}-\mathrm{H}, J=1.50 \mathrm{~Hz}, J=6.00 \mathrm{~Hz}\right), 7.90(\mathrm{~d}, 1 \mathrm{H}$, $\left.\mathrm{C}_{8}-\mathrm{H}, J=8.50 \mathrm{~Hz}\right), 7.94\left(\mathrm{~s}, 1 \mathrm{H}, \mathrm{C}_{2}^{\prime}-\mathrm{H}\right), 7.99\left(\mathrm{dd}, 1 \mathrm{H}, \mathrm{C}_{6}{ }^{\prime}-\mathrm{H}, J=2.00 \mathrm{~Hz}\right.$, $J=5.00 \mathrm{~Hz}), 8.14\left(\mathrm{~d}, 1 \mathrm{H}, \mathrm{C}_{10}-\mathrm{H}, J=8.00 \mathrm{~Hz}\right), 9.29\left(\mathrm{~d}, 1 \mathrm{H}, \mathrm{C}_{1}-\mathrm{H}, J=8.50\right.$ $\mathrm{Hz}), 9.68\left(\mathrm{~d}, 1 \mathrm{H}, \mathrm{C}_{13}-\mathrm{H}, J=8.00 \mathrm{~Hz}\right) ;{ }^{13} \mathrm{C} \mathrm{NMR}\left(125 \mathrm{MHz}, \mathrm{CDCl}_{3}\right)(\mathrm{ppm})$ $\delta_{\mathrm{C}}: 20.77\left(\mathrm{C}_{6}-\mathrm{CH}_{3}\right), 28.75\left(\mathrm{C}_{2}-\mathrm{CH}_{3}\right), 117.85\left(\mathrm{C}_{6 \mathrm{a}}\right), 123.03\left(\mathrm{C}_{1}\right), 124.67$ $\left(\mathrm{C}_{9}\right), 125.31\left(\mathrm{C}_{8}\right), 125.68\left(\mathrm{C}_{7 \mathrm{a}}\right), 126.25\left(\mathrm{C}_{13}\right), 126.58\left(\mathrm{C}_{14 \mathrm{~b}}\right), 127.41\left(\mathrm{C}_{12}\right)$, $127.82\left(\mathrm{C}_{10}\right), 128.33\left(\mathrm{C}_{4}\right), 128.84\left(\mathrm{C}_{5}^{\prime}\right), 128.91\left(\mathrm{C}_{3}\right), 129.57\left(\mathrm{C}_{11}\right), 131.19$ $\left(\mathrm{C}_{2}\right), 132.44\left(\mathrm{C}_{9 \mathrm{a}}\right), 133.92\left(\mathrm{C}_{3}^{\prime}\right), 134.76\left(\mathrm{C}_{13 \mathrm{a}}\right), 135.04\left(\mathrm{C}_{4}^{\prime}\right), 139.10\left(\mathrm{C}_{7}\right)$, $146.21\left(\mathrm{C}_{13 \mathrm{~b}}\right), 147.68\left(\mathrm{C}_{2}^{\prime}\right), 147.74\left(\mathrm{C}_{14 \mathrm{a}}\right), 149.11\left(\mathrm{C}_{6}^{\prime}\right), 150.36\left(\mathrm{C}_{4 \mathrm{a}}\right)$, $158.32\left(\mathrm{C}_{6}\right) ; \mathrm{MS}(\mathrm{EI}) \mathrm{m} / \mathrm{z}(\%) 385\left(\mathrm{M}^{+}, 100\right)$; Anal. Calcd. for $\mathrm{C}_{27} \mathrm{H}_{19} \mathrm{~N}_{3}$ (385): C, 84.13; H, 4.97; N, 10.90; Found : C 88.07, H 5.00, N 10.93\%.

2-Chloro-6-methyl-7-(pyridin-3'-yl)benzo[ $[h]$ naphtho[ $[1,2-b]$ [1,6]naphthyridine (7b): Pale yellow solid; $\mathrm{mp}$ : $240-242^{\circ} \mathrm{C}$; Yield: (40\%); IR (KBr, cm $\left.{ }^{-1}\right) v_{\max }: 1655(\mathrm{C}=\mathrm{N}), 1611,1568 ;{ }^{1} \mathrm{H}$ NMR $(500$ $\left.\mathrm{MHz}, \mathrm{CDCl}_{3}\right)(\mathrm{ppm}) \delta_{\mathrm{H}}: 2.85\left(\mathrm{~s}, 3 \mathrm{H}, \mathrm{C}_{6}-\mathrm{CH}_{3}\right), 7.15\left(\mathrm{~d}, 1 \mathrm{H}, \mathrm{C}_{3}-\mathrm{H}, J=9.00\right.$ $\mathrm{Hz}), 7.28$ (dd, $\left.1 \mathrm{H}, \mathrm{C}_{5}{ }^{\prime}-\mathrm{H}, J=8.50 \mathrm{~Hz}, J=5.00 \mathrm{~Hz}\right), 7.35-7.71\left(\mathrm{~m}, 4 \mathrm{H}, \mathrm{C}_{4}\right.$ $\mathrm{C}_{9}, \mathrm{C}_{11}$ and $\left.\mathrm{C}_{12}-\mathrm{H}\right), 7.83\left(\mathrm{dd}, 1 \mathrm{H}, \mathrm{C}_{4}^{\prime}-\mathrm{H}, J=1.50 \mathrm{~Hz}, J=6.00 \mathrm{~Hz}\right), 7.90(\mathrm{~d}$, $\left.1 \mathrm{H}, \mathrm{C}_{8}-\mathrm{H}, J=8.50 \mathrm{~Hz}\right), 7.96\left(\mathrm{~s}, 1 \mathrm{H}, \mathrm{C}_{2}{ }^{\prime}-\mathrm{H}\right), 7.81\left(\mathrm{dd}, 1 \mathrm{H}, \mathrm{C}_{6}^{\prime}-\mathrm{H}, J=2.00\right.$ $\mathrm{Hz}, J=5.00 \mathrm{~Hz}), 8.18\left(\mathrm{~d}, 1 \mathrm{H}, \mathrm{C}_{10}-\mathrm{H}, J=8.00 \mathrm{~Hz}\right), 9.36\left(\mathrm{~d}, 1 \mathrm{H}, \mathrm{C}_{1}-\mathrm{H}\right.$, $J=8.50 \mathrm{~Hz}), 9.72\left(\mathrm{~d}, 1 \mathrm{H}, \mathrm{C}_{13}-\mathrm{H}, J=8.00 \mathrm{~Hz}\right) ;{ }^{13} \mathrm{C} \mathrm{NMR}\left(125 \mathrm{MHz}, \mathrm{CDCl}_{3}\right)$ $(\mathrm{ppm}) \delta_{\mathrm{C}}: 16.9\left(\mathrm{C}_{6}-\mathrm{CH}_{3}\right), 24.4\left(\mathrm{C}_{7}-\mathrm{CH}_{3}\right), 118.1\left(\mathrm{C}_{6 \mathrm{a}}\right), 122.2\left(\mathrm{C}_{1}\right), 124.1$ $\left(\mathrm{C}_{9}\right), 125.2\left(\mathrm{C}_{8}\right), 125.4\left(\mathrm{C}_{7 \mathrm{a}}\right), 125.9\left(\mathrm{C}_{13}\right), 126.4\left(\mathrm{C}_{14 \mathrm{~b}}\right), 127.3\left(\mathrm{C}_{12}\right), 127.6$ $\left(\mathrm{C}_{10}\right), 128.0\left(\mathrm{C}_{4}\right), 128.6\left(\mathrm{C}_{3}\right), 128.9\left(\mathrm{C}_{5}^{\prime}\right), 129.6\left(\mathrm{C}_{11}\right), 131.0\left(\mathrm{C}_{2}\right), 131.1$ $\left(\mathrm{C}_{9 \mathrm{a}}\right), 133.5\left(\mathrm{C}_{3}^{\prime}\right), 133.9\left(\mathrm{C}_{13 \mathrm{a}}\right), 135.9\left(\mathrm{C}_{4}^{\prime}\right), 139.1\left(\mathrm{C}_{7}\right), 144.4\left(\mathrm{C}_{13 \mathrm{~b}}\right), 146.8$ $\left(\mathrm{C}_{2}^{\prime}\right), 147.4\left(\mathrm{C}_{14 \mathrm{a}}\right), 148.8\left(\mathrm{C}_{6}^{\prime}\right), 151.6\left(\mathrm{C}_{4 \mathrm{a}}\right), 158.6\left(\mathrm{C}_{6}\right) ; \mathrm{MS}(\mathrm{EI}) \mathrm{m} / \mathrm{z}(\%)$
405 ( $\left.\mathrm{M}^{+}, 100\right)$; Anal. Calcd. for $\mathrm{C}_{26} \mathrm{H}_{16} \mathrm{ClN}_{3}$ (405): C, 76.94; H, 3.97; N, 10.35; Found: C, $76.98 ; \mathrm{H}, 3.93$; N, $10.31 \%$.

2,6-Dimethyl-7-(furan-2'-yl)benzo[ $h]$ naphtho $[1,2-b][1,6]$ naphthyridine (8a): Colourless prisms; $\mathrm{mp}$ : $262-264^{\circ} \mathrm{C}$; Yield: $(43 \%)$; IR $\left(\mathrm{KBr}, \mathrm{cm}^{-1}\right) v_{\max }: 1620(\mathrm{C}=\mathrm{N}), 1587 ;{ }^{1} \mathrm{H}$ NMR $\left(500 \mathrm{MHz}, \mathrm{CDCl}_{3}\right)$ $(\mathrm{ppm}) \delta_{\mathrm{H}}: 2.29\left(\mathrm{~s}, 3 \mathrm{H}, \mathrm{C}_{2}-\mathrm{CH}_{3}\right), 2.80\left(\mathrm{~s}, 3 \mathrm{H}, \mathrm{C}_{6}-\mathrm{CH}_{3}\right), 6.65\left(\mathrm{t}, 1 \mathrm{H}, \mathrm{C}_{4}-\mathrm{H}\right.$, $J=3.50 \mathrm{~Hz}, J=1.50 \mathrm{~Hz}), 7.20\left(\mathrm{~d}, 1 \mathrm{H}, \mathrm{C}_{3}-\mathrm{H}, J=2.00 \mathrm{~Hz}\right), 7.33(\mathrm{dd}, 1 \mathrm{H}$, $\left.\mathrm{C}_{3}^{\prime}-\mathrm{H}, J=3.00 \mathrm{~Hz}, J=1.00 \mathrm{~Hz}\right), 7.45-8.02\left(\mathrm{~m}, 6 \mathrm{H}, \mathrm{C}_{4}, \mathrm{C}_{8}, \mathrm{C}_{7}, \mathrm{C}_{9}, \mathrm{C}_{12}\right.$, $\left.\mathrm{C}_{5}^{\prime}-\mathrm{H}\right), 8.27\left(\mathrm{~d}, 1 \mathrm{H}, \mathrm{C}_{10}-\mathrm{H}, J=8.00 \mathrm{~Hz}\right), 9.29\left(\mathrm{~d}, 1 \mathrm{H}, \mathrm{C}_{1}-\mathrm{H} J=1.50 \mathrm{~Hz}\right)$, $9.62\left(\mathrm{~d}, 1 \mathrm{H}, \mathrm{C}_{13}-\mathrm{H} J=8.50 \mathrm{~Hz}\right) ;{ }^{13} \mathrm{C} \mathrm{NMR}\left(125 \mathrm{MHz}, \mathrm{CDCl}_{3}\right)(\mathrm{ppm}) \delta_{\mathrm{C}}$ : $16.98\left(\mathrm{C}_{6}-\mathrm{CH}_{3}\right), 27.75\left(\mathrm{C}_{2}-\mathrm{CH}_{3}\right), 112.55\left(\mathrm{C}_{4}^{\prime}\right), 117.90\left(\mathrm{C}_{6 \mathrm{a}}\right), 120.44\left(\mathrm{C}_{3}^{\prime}\right)$, $122.81\left(\mathrm{C}_{1}\right), 124.42\left(\mathrm{C}_{9}\right), 125.34\left(\mathrm{C}_{8}\right), 125.49\left(\mathrm{C}_{7}\right), 125.90\left(\mathrm{C}_{13}\right), 126.38$ $\left(\mathrm{C}_{14 \mathrm{~b}}\right), 127.40\left(\mathrm{C}_{12}\right), 127.74\left(\mathrm{C}_{10}\right), 128.11\left(\mathrm{C}_{4}\right), 128.67\left(\mathrm{C}_{3}\right), 129.59\left(\mathrm{C}_{11}\right)$, $131.05\left(\mathrm{C}_{2}\right), 131.92\left(\mathrm{C}_{9 \mathrm{a}}\right), 133.83\left(\mathrm{C}_{13 \mathrm{a}}\right), 139.19\left(\mathrm{C}_{7}\right), 142.63\left(\mathrm{C}_{5}^{\prime}\right), 146.33$ $\left(\mathrm{C}_{13 \mathrm{~b}}\right), 147.22\left(\mathrm{C}_{14 \mathrm{a}}\right), 147.21\left(\mathrm{C}_{2}^{\prime}\right), 147.88\left(\mathrm{C}_{4 \mathrm{a}}\right), 157.91\left(\mathrm{C}_{6}\right) ; \mathrm{MS}(\mathrm{EI}) \mathrm{m} / \mathrm{z}$ (\%) $374\left(\mathrm{M}^{+}\right.$, 100); Anal. Calcd. for $\mathrm{C}_{26} \mathrm{H}_{18} \mathrm{~N}_{2} \mathrm{O}$ (374): C, 83.40; $\mathrm{H}, 4.85$; N, 7.48; Found: C, 83.33; H, 4.91; N, 7.54\%.

2-Chloro-7-(furan-2'-yl)-6-methylbenzo[ $h]$ naphtho[ $[1,2-b][1,6]$ naphthyridine (8b): Colourless solid; mp: $255-257^{\circ} \mathrm{C}$; Yield: $(40 \%)$; IR $\left(\mathrm{KBr}, \mathrm{cm}^{-1}\right) v_{\max }: 1619(\mathrm{C}=\mathrm{N}), 1572 ;{ }^{1} \mathrm{H}$ NMR $\left(500 \mathrm{MHz}, \mathrm{CDCl}_{3}\right)$ $(\mathrm{ppm}) \delta_{\mathrm{H}}: 2.77\left(\mathrm{~s}, 3 \mathrm{H}, \mathrm{C}_{6}-\mathrm{CH}_{3}\right), 6.69\left(\mathrm{dd}, 1 \mathrm{H}, \mathrm{C}_{4}^{\prime}-\mathrm{H}, J=3.50 \mathrm{~Hz}, J=1.5\right.$ $\mathrm{Hz}), 7.23\left(\mathrm{~d}, 1 \mathrm{H}, \mathrm{C}_{3}-\mathrm{H}, J=2.00 \mathrm{~Hz}\right), 7.30\left(\mathrm{dd}, 1 \mathrm{H}, \mathrm{C}_{3}^{\prime}-\mathrm{H}, J=3.00 \mathrm{~Hz}\right.$, $J=1.00 \mathrm{~Hz}), 7.49-8.01\left(\mathrm{~m}, 6 \mathrm{H}, \mathrm{C}_{4}, \mathrm{C}_{8}, \mathrm{C}_{7}, \mathrm{C}_{9}, \mathrm{C}_{12}, \mathrm{C}_{5}^{\prime}-\mathrm{H}\right), 8.29(\mathrm{~d}, 1 \mathrm{H}$, $\left.\mathrm{C}_{10}-\mathrm{H}, J=8.00 \mathrm{~Hz}\right), 9.31\left(\mathrm{~d}, 1 \mathrm{H}, \mathrm{C}_{1}-\mathrm{H}, J=1.50 \mathrm{~Hz}\right), 9.65\left(\mathrm{~d}, 1 \mathrm{H}, \mathrm{C}_{13}-\mathrm{H}\right.$ $J=8.50 \mathrm{~Hz}) ;{ }^{13} \mathrm{C}$ NMR $\left(125 \mathrm{MHz}, \mathrm{CDCl}_{3}\right)(\mathrm{ppm}) \delta_{\mathrm{C}}: 17.24\left(\mathrm{C}_{6}-\mathrm{CH}_{3}\right)$, $112.43\left(\mathrm{C}_{4}^{\prime}\right), 118.52\left(\mathrm{C}_{62}\right), 120.91\left(\mathrm{C}_{3}^{\prime}\right), 122.65\left(\mathrm{C}_{1}\right), 124.27\left(\mathrm{C}_{9}\right), 125.22$ $\left(\mathrm{C}_{8}\right), 125.29\left(\mathrm{C}_{7 \mathrm{a}}\right), 125.60\left(\mathrm{C}_{13}\right), 126.19\left(\mathrm{C}_{14 \mathrm{~b}}\right), 127.35\left(\mathrm{C}_{12}\right), 127.77\left(\mathrm{C}_{10}\right)$, $128.34\left(\mathrm{C}_{4}\right), 128.71\left(\mathrm{C}_{3}\right), 129.60\left(\mathrm{C}_{11}\right), 130.99\left(\mathrm{C}_{2}\right), 131.43\left(\mathrm{C}_{9 \mathrm{a}}\right), 134.11$ $\left(\mathrm{C}_{13}\right), 139.35,\left(\mathrm{C}_{7}\right), 142.56\left(\mathrm{C}_{5}^{\prime}\right), 144.4\left(\mathrm{C}_{13 \mathrm{~b}}\right), 147.4\left(\mathrm{C}_{14 \mathrm{a}}\right), 147.67\left(\mathrm{C}_{4 \mathrm{a}}\right)$, $148.59\left(\mathrm{C}_{2}^{\prime}\right) 158.09\left(\mathrm{C}_{6}\right)$; MS (EI) m/z (\%) $396(\mathrm{M}+2,35)$, $394\left(\mathrm{M}^{+}, 100\right)$; Anal. Calcd. for $\mathrm{C}_{25} \mathrm{H}_{15} \mathrm{ClN}_{2} \mathrm{O}$ (394): C, 76.05; H, 3.83; N, 7.09; Found : C 76.12, H 3.86, N 7.14\%.

2,6-Dimethyl-7-(thiophen-2'-yl)benzo[ $h]$ naphtho[ $[1,2-b][1,6]$ naphthyridine (9a): Colourless prisms; $\mathrm{mp}: 230-231^{\circ} \mathrm{C}$; Yield: $(33 \%)$ IR $\left(\mathrm{KBr}, \mathrm{cm}^{-1}\right) v_{\max }: 1612(\mathrm{C}=\mathrm{N}), 1555 ;{ }^{1} \mathrm{H}$ NMR $\left(500 \mathrm{MHz}, \mathrm{CDCl}_{3}\right)$ $(\mathrm{ppm}) \delta_{\mathrm{H}}: 2.25\left(\mathrm{~s}, 3 \mathrm{H}, \mathrm{C}_{2}-\mathrm{CH}_{3}\right), 2.86\left(\mathrm{~s}, 3 \mathrm{H}, \mathrm{C}_{6}-\mathrm{CH}_{3}\right), 7.01\left(\mathrm{~d}, 1 \mathrm{H}, \mathrm{C}_{3}-\right.$ $\mathrm{H}, J=8.50 \mathrm{~Hz}), 7.17\left(\mathrm{t}, 2 \mathrm{H}, \mathrm{C}_{4}^{\prime}-\mathrm{H}, J=5.00 \mathrm{~Hz}\right) 7.64\left(\mathrm{~d}, 1 \mathrm{H}, \mathrm{C}_{9}-\mathrm{H}, J=8.50\right.$ $\mathrm{Hz}), 7.69\left(\mathrm{dd}, 1 \mathrm{H}, \mathrm{C}_{5}^{\prime}-\mathrm{H}, J=5.50 \mathrm{~Hz}, J=1.00 \mathrm{~Hz}\right), 7.73-7.89\left(\mathrm{~m}, 4 \mathrm{H}, \mathrm{C}_{4}\right.$, $\mathrm{C}_{8}, \mathrm{C}_{11}, \mathrm{C}_{12}-\mathrm{H}$ ), 7.95 (dd, $1 \mathrm{H}, \mathrm{C}_{3}^{\prime}-\mathrm{H} J=4.50 \mathrm{~Hz}, J=1.50 \mathrm{~Hz}$ ), 8.15 (d, $1 \mathrm{H}$, $\left.\mathrm{C}_{10}-\mathrm{H}, J=7.50 \mathrm{~Hz}\right), 9.21\left(\mathrm{~d}, 1 \mathrm{H}, \mathrm{C}_{1}-\mathrm{H} J=7.50 \mathrm{~Hz}\right), 9.50\left(\mathrm{~d}, 1 \mathrm{H}, \mathrm{C}_{13}-\mathrm{H}\right.$, $J=8.00 \mathrm{~Hz}) ;{ }^{13} \mathrm{C}$ NMR $\left(125 \mathrm{MHz}, \mathrm{CDCl}_{3}\right)(\mathrm{ppm}) \delta_{\mathrm{C}}: 20.77\left(\mathrm{C}_{6}-\mathrm{CH}_{3}\right)$, $28.75\left(\mathrm{C}_{2}-\mathrm{CH}_{3}\right), 117.85\left(\mathrm{C}_{6 \mathrm{a}}\right), 123.03\left(\mathrm{C}_{1}\right), 124.67\left(\mathrm{C}_{9}\right), 125.31\left(\mathrm{C}_{8}\right)$, $125.68\left(\mathrm{C}_{7 \mathrm{a}}\right), 126.25\left(\mathrm{C}_{13}\right), 126.58\left(\mathrm{C}_{14 \mathrm{~b}}\right), 127.41\left(\mathrm{C}_{12}\right), 127.82\left(\mathrm{C}_{10}\right)$, $128.33\left(\mathrm{C}_{4}\right), 128.74\left(\mathrm{C}_{3}^{\prime}\right), 128.91\left(\mathrm{C}_{3}\right), 129.57\left(\mathrm{C}_{11}\right), 131.19\left(\mathrm{C}_{2}\right), 132.44$ $\left(\mathrm{C}_{9 \mathrm{a}}\right), 133.92\left(\mathrm{C}_{4}^{\prime}\right), 134.76\left(\mathrm{C}_{13 \mathrm{a}}\right), 135.04\left(\mathrm{C}_{5}^{\prime}\right), 137.68\left(\mathrm{C}_{2}^{\prime}\right), 139.10\left(\mathrm{C}_{7}\right)$, $146.21\left(\mathrm{C}_{13 \mathrm{~b}}\right), 147.74\left(\mathrm{C}_{14 \mathrm{a}}\right), 150.36\left(\mathrm{C}_{4 \mathrm{a}}\right), 158.32\left(\mathrm{C}_{6}\right) ; \mathrm{MS}(\mathrm{EI}) \mathrm{m} / \mathrm{z}(\%)$ $390\left(\mathrm{M}^{+}, 100\right)$; Anal. Calcd. for $\mathrm{C}_{26} \mathrm{H}_{18} \mathrm{~N}_{2} \mathrm{~S}(390)$ : C, 79.97; $\mathrm{H}, 4.65 ; \mathrm{N}$, 7.17; S, 8.21; Found: C, 79.92; H, 4.62; N, 7.22; S, 8.24\%.

2-Chloro-6-methyl-7-(thiophen-2'-yl)benzo[ $h]$ naphtho[ $[1,2-b]$ [1,6]naphthyridine (9b): Colourless prisms; mp: $231-233^{\circ} \mathrm{C}$; Yield: (32\%); IR $\left(\mathrm{KBr}, \mathrm{cm}^{-1}\right) v_{\max }: 1600(\mathrm{C}=\mathrm{N}), 1581 ;{ }^{1} \mathrm{H}$ NMR $(500 \mathrm{MHz}$, $\left.\mathrm{CDCl}_{3}\right)(\mathrm{ppm}) \delta_{\mathrm{H}}: 2.75\left(\mathrm{~s}, 3 \mathrm{H}, \mathrm{C}_{6}-\mathrm{CH}_{3}\right), 7.00\left(\mathrm{~d}, 1 \mathrm{H}, \mathrm{C}_{3}-\mathrm{H}, J=8.50 \mathrm{~Hz}\right)$, $7.20\left(\mathrm{t}, 1 \mathrm{H}, \mathrm{C}_{4}^{\prime}-\mathrm{H}, J=4.50 \mathrm{~Hz}\right), 7.60\left(\mathrm{~d}, 1 \mathrm{H}, \mathrm{C}_{9}-\mathrm{H}, J=8.00 \mathrm{~Hz}\right), 7.65(\mathrm{dd}$, $\left.1 \mathrm{H}, \mathrm{C}_{5}^{\prime}-\mathrm{H}, J=5.00 \mathrm{~Hz}, J=1.00 \mathrm{~Hz}\right), 7.71-7.86\left(\mathrm{~m}, 4 \mathrm{H}, \mathrm{C}_{4}, \mathrm{C}_{8}, \mathrm{C}_{11}, \mathrm{C}_{12}-\mathrm{H}\right)$, $7.93\left(\mathrm{dd}, 1 \mathrm{H}, \mathrm{C}_{3}{ }^{\prime}-\mathrm{H}, J=4.00 \mathrm{~Hz}, J=1.50 \mathrm{~Hz}\right), 8.12\left(\mathrm{~d}, 1 \mathrm{H}, \mathrm{C}_{10}-\mathrm{H}, J=7.50\right.$ $\mathrm{Hz}), 9.25\left(\mathrm{~d}, 1 \mathrm{H}, \mathrm{C}_{1}-\mathrm{H}, J=8.00 \mathrm{~Hz}\right), 9.56\left(\mathrm{~d}, 1 \mathrm{H}, \mathrm{C}_{13}-\mathrm{H} \mathrm{J}=8.50 \mathrm{~Hz}\right)$; ${ }^{13} \mathrm{C}$ NMR $\left(125 \mathrm{MHz}, \mathrm{CDCl}_{3}\right)(\mathrm{ppm}) \delta_{\mathrm{C}}: 22.27\left(\mathrm{C}_{6}-\mathrm{CH}_{3}\right), 118.03\left(\mathrm{C}_{62}\right)$, $122.43\left(\mathrm{C}_{1}\right), 124.47\left(\mathrm{C}_{9}\right), 125.28\left(\mathrm{C}_{8}\right), 125.54\left(\mathrm{C}_{7 \mathrm{a}}\right), 126.16\left(\mathrm{C}_{13}\right), 126.32$ $\left(\mathrm{C}_{14 \mathrm{~b}}\right), 127.28\left(\mathrm{C}_{12}\right), 127.75\left(\mathrm{C}_{10}\right), 128.01\left(\mathrm{C}_{4}\right), 128.56\left(\mathrm{C}_{3}\right), 128.98\left(\mathrm{C}_{3}\right)$, $129.91\left(\mathrm{C}_{11}\right), 130.86\left(\mathrm{C}_{2}\right), 132.44\left(\mathrm{C}_{9 \mathrm{a}}\right), 133.92\left(\mathrm{C}_{4}^{\prime}\right), 134.45\left(\mathrm{C}_{13 \mathrm{a}}\right), 134.99$ 
$\left(\mathrm{C}_{5}^{\prime}\right), 137.89\left(\mathrm{C}_{2}^{\prime}\right), 138.93\left(\mathrm{C}_{7}\right), 146.46\left(\mathrm{C}_{13 \mathrm{~b}}\right), 147.62\left(\mathrm{C}_{14 \mathrm{a}}\right), 149.37$ $\left(\mathrm{C}_{4 \mathrm{a}}\right), 159.43\left(\mathrm{C}_{6}\right) ; \mathrm{MS}(\mathrm{EI}) \mathrm{m} / \mathrm{z}(\%) 410\left(\mathrm{M}^{+}, 100\right)$; Anal. Calcd. For $\mathrm{C}_{25} \mathrm{H}_{15} \mathrm{ClN}_{2} \mathrm{~S}(410)$ : C, 73.07; H, 3.68; N, 6.82; S, 7.80; Found: C, 73.10; $\mathrm{H}, 3.62 ; \mathrm{N}, 6.85 ; \mathrm{S}, 7.77 \%$.

Preparation of 2-methyl-N-phenylbenzo[h]quinolin-4-amine (15) general procedure: 4-Chloro-2-methylbenzo[ $h]$ quinoline (10, $0.004 \mathrm{~mol})$ was reacted with $p$-toluidine and $p$-chloroaniline $(0.004$ mol) under neat condition at $190^{\circ} \mathrm{C}$ for half an hour. The product was washed with water, dried, adsorbed and purified using silica gel column chromatography and eluted with ethylacetate: methanol (95:5) mixture to get 12 which was then recrystallised using methanol.

2-Methyl- $N$ - $p$-tolylbenzo[ $h]$ quinolin-4-amine $\quad(12 a)$ : Brown solid; mp: $295-297^{\circ} \mathrm{C}$; Yield: (73\%); IR $\left(\mathrm{KBr}, \mathrm{cm}^{-1}\right) v_{\max }: 3371(\mathrm{NH})$, $1628(\mathrm{C}=\mathrm{N}), 1138 ;{ }^{1} \mathrm{H}$ NMR $\left(400 \mathrm{MHz}, \mathrm{DMSO}-d_{6}\right)(\mathrm{ppm}) \delta_{\mathrm{H}}: 2.37(\mathrm{~s}$, $\left.3 \mathrm{H}, \mathrm{C}_{4}{ }^{\prime}-\mathrm{CH}_{3}\right), 2.70\left(\mathrm{~s}, 3 \mathrm{H}, \mathrm{C}_{2}-\mathrm{CH}_{3}\right), 6.63\left(\mathrm{~s}, 1 \mathrm{H}, \mathrm{C}_{3}-\mathrm{H}\right), 7.62-8.52(\mathrm{~m}$, $\left.9 \mathrm{H}, \mathrm{C}_{5}, \mathrm{C}_{6}, \mathrm{C}_{7}, \mathrm{C}_{8}, \mathrm{C}_{9}, \mathrm{C}_{2}^{\prime}, \mathrm{C}_{3}{ }^{\prime}, \mathrm{C}_{5}{ }^{\prime}, \mathrm{C}_{6}^{\prime}-\mathrm{H}\right), 9.27\left(\mathrm{dd}, 1 \mathrm{H}, J_{0}=8.80 \mathrm{~Hz}\right.$, $\left.J_{m}=2.00 \mathrm{~Hz}, \mathrm{C}_{10}-\mathrm{H}\right), 10.35\left(\mathrm{~s}, 1 \mathrm{H}, \mathrm{C}_{4}-\mathrm{NH}\right.$ amino form), $13.56(\mathrm{~s}, 1 \mathrm{H}$, $\mathrm{C}_{1}-\mathrm{NH}$ imino form, ratio of amino form : imino form is $\left.1: 1\right) ;{ }^{13} \mathrm{C}$ NMR $\left(100 \mathrm{MHz}, \mathrm{DMSO}-d_{6}\right)(\mathrm{ppm}) \delta_{\mathrm{C}}: 19.2\left(\mathrm{C}_{4}^{\prime}-\mathrm{CH}_{3}\right), 20.5\left(\mathrm{C}_{2}-\mathrm{CH}_{3}\right) 102.6$ $\left(\mathrm{C}_{3}\right), 119.1\left(\mathrm{C}_{6}^{\prime}\right.$ and $\left.\mathrm{C}_{2}^{\prime}\right), 119.2\left(\mathrm{C}_{4 \mathrm{a}}\right), 124.0\left(\mathrm{C}_{5}\right), 128.1\left(\mathrm{C}_{10}\right), 128.2\left(\mathrm{C}_{6}\right)$, $128.6\left(\mathrm{C}_{9}\right), 128.7\left(\mathrm{C}_{8}\right), 129.1\left(\mathrm{C}_{7}\right), 130.6\left(\mathrm{C}_{3}^{\prime}\right.$ and $\left.\mathrm{C}_{5}{ }^{\prime}\right), 131.9\left(\mathrm{C}_{4}^{\prime}\right), 134.6$ $\left(\mathrm{C}_{10 \mathrm{a}}\right), 135.8\left(\mathrm{C}_{6 \mathrm{a}}\right), 139.0\left(\mathrm{C}_{1}^{\prime}\right), 140.7\left(\mathrm{C}_{10 \mathrm{~b}}\right), 154.0\left(\mathrm{C}_{4}\right), 154.2\left(\mathrm{C}_{2}\right)$; Anal. Calcd. for $\mathrm{C}_{21} \mathrm{H}_{18} \mathrm{~N}_{2}$ (298): C 84.53; H, 6.08, N 9.39; Found : C 84.64, H $5.99, \mathrm{~N} 9.37 \%$.

$N$-(4'-chlorophenyl)-2-methylbenzo[h]quinolin-4-amine (12b): Brown solid; mp: $294-296^{\circ} \mathrm{C}$; Yield: $(72 \%)$; IR $\left(\mathrm{KBr}, \mathrm{cm}^{-1}\right) v_{\max }: 3401$ $(\mathrm{NH}), 1647(\mathrm{C}=\mathrm{N}), 1197 ;{ }^{1} \mathrm{H}$ NMR $\left(400 \mathrm{MHz}, \mathrm{DMSO}-d_{6}\right)(\mathrm{ppm}) \delta_{\mathrm{H}}$ : $2.76\left(\mathrm{~s}, 3 \mathrm{H}, \mathrm{C}_{2}-\mathrm{CH}_{3}\right), 6.97\left(\mathrm{~s}, 1 \mathrm{H}, \mathrm{C}_{3}-\mathrm{H}\right), 7.51-8.54\left(\mathrm{~m}, 9 \mathrm{H}, \mathrm{C}_{5}, \mathrm{C}_{6}\right.$, $\left.\mathrm{C}_{7}, \mathrm{C}_{8}, \mathrm{C}_{9}, \mathrm{C}_{2}^{\prime}, \mathrm{C}_{3}{ }^{\prime}, \mathrm{C}_{5}{ }_{5}, \mathrm{C}_{6}{ }^{\prime}-\mathrm{H}\right), 9.25\left(\mathrm{dd}, 1 \mathrm{H}, J_{0}=8.40 \mathrm{~Hz}, J_{m}=1.50 \mathrm{~Hz}\right.$, $\left.\mathrm{C}_{10}-\mathrm{H}\right), 10.69\left(\mathrm{~s}, 1 \mathrm{H}, \mathrm{C}_{4}-\mathrm{NH}\right.$ amino form $), 13.59$ (s, $1 \mathrm{H}, \mathrm{C}_{1}-\mathrm{NH}$ imino form, ratio of amino form : imino form is $1: 1) ;{ }^{13} \mathrm{C} \mathrm{NMR}(100 \mathrm{MHz}$, DMSO- $\left.d_{6}\right)(\mathrm{ppm}) \delta_{\mathrm{C}}: 20.5\left(\mathrm{C}_{2}-\mathrm{CH}_{3}\right), 102.6\left(\mathrm{C}_{3}\right), 119.2\left(\mathrm{C}_{4 \mathrm{a}}\right), 121.3\left(\mathrm{C}_{6}^{\prime}\right.$ and $\left.\mathrm{C}_{2}^{\prime}\right), 124.0\left(\mathrm{C}_{5}\right), 128.1\left(\mathrm{C}_{10}\right), 128.2\left(\mathrm{C}_{6}\right), 128.6\left(\mathrm{C}_{9}\right), 128.7\left(\mathrm{C}_{8}\right), 129.1$ $\left(\mathrm{C}_{7}\right), 129.9\left(\mathrm{C}_{4}^{\prime}\right), 130.4\left(\mathrm{C}_{3}{ }^{\prime}\right.$ and $\left.\mathrm{C}_{5}{ }^{\prime}\right), 134.6\left(\mathrm{C}_{10 \mathrm{a}}\right), 135.8\left(\mathrm{C}_{6 \mathrm{a}}\right), 140.7$ $\left(\mathrm{C}_{10 \mathrm{~b}}\right), 141.5\left(\mathrm{C}_{1}^{\prime}\right), 154.0\left(\mathrm{C}_{4}\right), 154.2\left(\mathrm{C}_{2}\right)$; Anal. Calcd. for $\mathrm{C}_{20} \mathrm{H}_{15} \mathrm{ClN}_{2}$ (318): C 75.35, H 4.74, N 8.79; Found : C 75.38, H 4.83, N 8.70\%.

\section{General procedure for the synthesis of compound $(13,14,15)$}

2-methyl- $N$-phenylbenzo[h]quinolin-4-amine (12) (0.002 mol) and benzoic acid/acetic acid/1-naphthoic acid $(0.0025 \mathrm{~mol})$ were added to polyphosphoric acid $\left(6 \mathrm{~g}\right.$ of $\mathrm{P}_{2} \mathrm{O}_{5}$ in $3 \mathrm{~mL}$ of $\left.\mathrm{H}_{3} \mathrm{PO}_{4}\right)$ and heated at $160^{\circ} \mathrm{C}$ for 3 hours. The reaction was monitored by using TLC. After the completion of the reaction, it was poured into ice water, neutralized with saturated sodium bicarbonate solution to remove excess of benzoic acid/acetic acid/1-naphthoic acid, extracted with ethyl acetate, purified by column chromatography using silica gel and product eluted with petroleum ether: ethyl acetate $(99: 1)$ mixture to get $13,14,15$ which was recrystallised using methanol.

6,9-Dimethyl-7-phenylbenzo $[b]$ naphtho $[1,2-h][1,6]$ naphthyridine (13a): Yellow prisms; mp: $202-204^{\circ} \mathrm{C}$; Yield: (54\%). IR $\left(\mathrm{KBr}, \mathrm{cm}^{-1}\right) v_{\max }: 1624(\mathrm{C}=\mathrm{N}), 1561,1536$ and $1484 ;{ }^{1} \mathrm{H}$ NMR $(500$ $\left.\mathrm{MHz}, \mathrm{CDCl}_{3}\right)(\mathrm{ppm}) \delta_{\mathrm{H}}: 2.38\left(\mathrm{~s}, 3 \mathrm{H}, \mathrm{C}_{6}-\mathrm{CH}_{3}\right), 3.15\left(\mathrm{~s}, 3 \mathrm{H}, \mathrm{C}_{9}-\mathrm{CH}_{3}\right)$, 7.35-7.98 (m, 10H, $\left.\mathrm{C}_{2}, \mathrm{C}_{3}, \mathrm{C}_{8}, \mathrm{C}_{9}, \mathrm{C}_{10}, \mathrm{C}_{11}, \mathrm{C}_{2}{ }^{\prime}, \mathrm{C}_{3}{ }^{\prime}, \mathrm{C}_{5}{ }^{\prime}, \mathrm{C}_{6}{ }^{\prime}-\mathrm{H}\right), 8.01(\mathrm{~d}$, $\left.1 \mathrm{H}, \mathrm{C}_{1}-\mathrm{H}, J=9.20 \mathrm{~Hz}\right), 8.25\left(\mathrm{~d}, 1 \mathrm{H}, \mathrm{C}_{14}-\mathrm{H}, J=8.08 \mathrm{~Hz}\right), 9.39\left(\mathrm{~d}, 1 \mathrm{H}, \mathrm{C}_{4}-\right.$ $\left.\mathrm{H}, J_{o}=8.00 \mathrm{~Hz}, J_{m}=2.00 \mathrm{~Hz}\right), 9.45\left(\mathrm{~d}, 1 \mathrm{H}, \mathrm{C}_{13}-\mathrm{H}, J=9.20 \mathrm{~Hz}\right) ;{ }^{13} \mathrm{C} \mathrm{NMR}$ $\left(125 \mathrm{MHz}, \mathrm{CDCl}_{3}\right)(\mathrm{ppm}) \delta_{\mathrm{C}}: 21.7\left(\mathrm{C}_{9}-\mathrm{CH}_{3}\right), 29.7\left(\mathrm{C}_{6}-\mathrm{CH}_{3}\right), 121.0\left(\mathrm{C}_{6 \mathrm{a}}\right)$, $122.1\left(\mathrm{C}_{13}\right), 122.4\left(\mathrm{C}_{7 \mathrm{a}}\right), 124.7\left(\mathrm{C}_{4}\right), 126.0\left(\mathrm{C}_{12 \mathrm{~b}}\right), 126.5\left(\mathrm{C}_{3}\right), 127.0\left(\mathrm{C}_{14}^{\mathrm{a}}\right)$, 127.4 $\left(\mathrm{C}_{2}\right), 127.8\left(\mathrm{C}_{1}\right), 128.3\left(\mathrm{C}_{3}{ }^{\prime}, \mathrm{C}_{4}{ }^{\prime}, \mathrm{C}_{5}{ }^{\prime}\right), 128.5\left(\mathrm{C}_{2}{ }^{\prime}\right.$ and $\left.\mathrm{C}_{6}{ }^{\prime}\right), 129.1\left(\mathrm{C}_{8}\right)$, $130.0\left(\mathrm{C}_{4 \mathrm{a}}\right), 130.7\left(\mathrm{C}_{14 \mathrm{a}}\right), 130.9\left(\mathrm{C}_{11}\right), 132.6\left(\mathrm{C}_{10}\right), 133.4\left(\mathrm{C}_{11 \mathrm{a}}\right), 134.9\left(\mathrm{C}_{9}\right)$, $135.1\left(\mathrm{C}_{1}^{\prime}\right), 137.5\left(\mathrm{C}_{7}\right)$ 148.4 $\left(\mathrm{C}_{4 \mathrm{~b}}\right), 149.0\left(\mathrm{C}_{12 \mathrm{a}}\right), 159.4\left(\mathrm{C}_{6}\right)$; Anal. Calcd. for $\mathrm{C}_{28} \mathrm{H}_{20} \mathrm{~N}_{2}$ (384) C, 87.47; H, 5.24; N, 7.29. Found : C, 87.41, H 5.27, $\mathrm{N} 7.32 \%$.

9-Chloro-6-methyl-7-phenylbenzo $[b]$ naphtho $[1,2-h][1,6]$ naphthyridine (13b): Pale yellow solid; mp: $208-210^{\circ} \mathrm{C}$; Yield: $(52 \%)$. IR $\left(\mathrm{KBr}, \mathrm{cm}^{-1}\right) v_{\max }: 1633(\mathrm{C}=\mathrm{N}), 1598,1538$ and $1469 ;{ }^{1} \mathrm{H}$ NMR $(400$ $\left.\mathrm{MHz}, \mathrm{CDCl}_{3}\right)(\mathrm{ppm}) \delta_{\mathrm{H}}: 2.45\left(\mathrm{~s}, 3 \mathrm{H}, \mathrm{C}_{6}-\mathrm{CH}_{3}\right), 7.49-8.02\left(\mathrm{~m}, 10 \mathrm{H}, \mathrm{C}_{2}\right.$, $\left.\mathrm{C}_{3}, \mathrm{C}_{8}, \mathrm{C}_{9}, \mathrm{C}_{10} \mathrm{C}_{11}, \mathrm{C}_{2}^{\prime}, \mathrm{C}_{3}, \mathrm{C}_{5}^{\prime}, \mathrm{C}_{6}{ }^{\prime}-\mathrm{H}\right), 8.10\left(\mathrm{~d}, 1 \mathrm{H}, \mathrm{C}_{1}-\mathrm{H}, J=8.80 \mathrm{~Hz}\right)$, $8.37\left(\mathrm{~d}, 1 \mathrm{H}, \mathrm{C}_{14}-\mathrm{H}, J=8.08 \mathrm{~Hz}\right), 9.36\left(\mathrm{~d}, 1 \mathrm{H}, \mathrm{C}_{4}-\mathrm{H}, J_{0}=8.80 \mathrm{~Hz}, J_{m}=2.00\right.$ $\mathrm{Hz}), 9.40\left(\mathrm{~d}, 1 \mathrm{H}, \mathrm{C}_{13}-\mathrm{H}, J=9.20 \mathrm{~Hz}\right) ;{ }^{13} \mathrm{C} \mathrm{NMR}\left(100 \mathrm{MHz}, \mathrm{CDCl}_{3}\right)(\mathrm{ppm})$ $\delta_{\mathrm{C}}: 29.7\left(\mathrm{C}_{6}-\mathrm{CH}_{3}\right), 121.0\left(\mathrm{C}_{6 \mathrm{a}}\right), 122.1\left(\mathrm{C}_{13}\right), 122.3\left(\mathrm{C}_{7 \mathrm{a}}\right), 124.7\left(\mathrm{C}_{4}\right), 126.0$ $\left(\mathrm{C}_{12 \mathrm{~b}}\right), 126.5\left(\mathrm{C}_{3}\right), 127.0\left(\mathrm{C}_{14}\right), 127.4\left(\mathrm{C}_{2}\right), 127.8\left(\mathrm{C}_{1}\right), 128.0\left(\mathrm{C}_{8}\right), 128.3$ $\left(\mathrm{C}_{3}^{\prime}, \mathrm{C}_{4}^{\prime}, \mathrm{C}_{5}^{\prime}\right), 128.5\left(\mathrm{C}_{2}^{\prime}\right.$ and $\left.\mathrm{C}_{6}^{\prime}\right), 129.3\left(\mathrm{C}_{9}\right), 130.0\left(\mathrm{C}_{4 \mathrm{a}}\right), 130.7\left(\mathrm{C}_{14 \mathrm{a}}\right)$, $131.1\left(\mathrm{C}_{11}\right), 132.8\left(\mathrm{C}_{10}\right), 133.1\left(\mathrm{C}_{11 \mathrm{a}}\right), 135.1\left(\mathrm{C}_{1}^{\prime}\right), 137.5\left(\mathrm{C}_{7}\right) 148.4\left(\mathrm{C}_{4 \mathrm{~b}}\right)$, $149.0\left(\mathrm{C}_{12 \mathrm{a}}\right), 159.4\left(\mathrm{C}_{6}\right)$; Anal. Calcd. for $\mathrm{C}_{27} \mathrm{H}_{17} \mathrm{ClN}_{2}(404): \mathrm{C} 80.09, \mathrm{H}$ 4.23, N 6.91; Found : C 80.11, H 4.27, N 6.98\%.

6,7,9-Trimethylbenzo $[b]$ naphtho $[1,2-h][1,6]$ naphthyridine (14a): Pale yellow prisms; mp: $172-174^{\circ} \mathrm{C}$; Yield: (54\%); IR $\left(\mathrm{KBr}, \mathrm{cm}^{-1}\right)$ $v_{\max }: 1620(\mathrm{C}=\mathrm{N}), 1558,1521 ;{ }^{1} \mathrm{H}$ NMR $\left(500 \mathrm{MHz}, \mathrm{CDCl}_{3}\right)(\mathrm{ppm}) \delta_{\mathrm{H}}$ : $2.64\left(\mathrm{~s}, 3 \mathrm{H}, \mathrm{C}_{6}-\mathrm{CH}_{3}\right), 3.36\left(\mathrm{~s}, 3 \mathrm{H}, \mathrm{C}_{9}-\mathrm{CH}_{3}\right), 3.39\left(\mathrm{~s}, 3 \mathrm{H}, \mathrm{C}_{7}-\mathrm{CH}_{3}\right), 7.70-$ $8.05\left(\mathrm{~m}, 5 \mathrm{H}, \mathrm{C}_{1}, \mathrm{C}_{2}, \mathrm{C}_{3}, \mathrm{C}_{10}, \mathrm{C}_{11}-\mathrm{H}\right), 8.09\left(\mathrm{~s}, 1 \mathrm{H}, \mathrm{C}_{8}-\mathrm{H}\right), 8.30(\mathrm{~d}, 1 \mathrm{H}$, $\left.\mathrm{C}_{14}-\mathrm{H}, J=8.00 \mathrm{~Hz}\right), 9.33\left(\mathrm{~d}, 1 \mathrm{H}, \mathrm{C}_{4}-\mathrm{H}, J_{o}=8.50 \mathrm{~Hz}, J_{m}=2.00 \mathrm{~Hz}\right), 9.37(\mathrm{~d}$, $\left.1 \mathrm{H}, \mathrm{C}_{13}-\mathrm{H}, J=9.00 \mathrm{~Hz}\right) ;{ }^{13} \mathrm{C} \mathrm{NMR}\left(125 \mathrm{MHz}, \mathrm{CDCl}_{3}\right)(\mathrm{ppm}) \delta_{\mathrm{C}}: 21.7\left(\mathrm{C}_{9}-\right.$ $\left.\mathrm{CH}_{3}\right), 24.56\left(\mathrm{C}_{7}-\mathrm{CH}_{3}\right), 29.7\left(\mathrm{C}_{6}-\mathrm{CH}_{3}\right), 120.76\left(\mathrm{C}_{6 \mathrm{a}}\right), 122.87\left(\mathrm{C}_{13}\right), 123.02$ $\left(\mathrm{C}_{7 \mathrm{a}}\right), 124.32\left(\mathrm{C}_{4}\right), 126.15\left(\mathrm{C}_{12 \mathrm{~b}}\right), 126.93\left(\mathrm{C}_{3}\right), 127.21\left(\mathrm{C}_{14}\right), 127.52\left(\mathrm{C}_{2}\right)$, $127.89\left(\mathrm{C}_{1}\right), 129.55\left(\mathrm{C}_{8}\right), 130.34\left(\mathrm{C}_{4 \mathrm{a}}\right), 130.97\left(\mathrm{C}_{14 \mathrm{a}}\right), 131.09\left(\mathrm{C}_{11}\right), 132.76$ $\left(\mathrm{C}_{10}\right), 133.39\left(\mathrm{C}_{11 \mathrm{a}}\right), 134.77\left(\mathrm{C}_{9}\right), 138.04\left(\mathrm{C}_{7}\right) 147.95\left(\mathrm{C}_{4 \mathrm{~b}}\right), 149.53\left(\mathrm{C}_{12 \mathrm{a}}\right)$, $159.31\left(\mathrm{C}_{6}\right)$; MS (EI) m/z (\%) $322\left(\mathrm{M}^{+}, 100\right)$; Anal. Calcd. for $\mathrm{C}_{23} \mathrm{H}_{18} \mathrm{~N}_{2}$ (322): C, 85.68; H, 5.63; N, 8.69; Found: C, 85.70; H, 5.64; N, 8.5\%.

9-Chloro-6,7-dimethylbenzo [b]naph tho $[1,2-h][1,6]$ naphthyridine (14b): Pale yellow prisms; $\mathrm{mp}$ : $170-172^{\circ} \mathrm{C}$; Yield: $(57 \%)$; IR $\left(\mathrm{KBr}, \mathrm{cm}^{-1}\right) v_{\max }: 1612(\mathrm{C}=\mathrm{N}), 1540,1513 ;{ }^{1} \mathrm{H}$ NMR $(400 \mathrm{MHz}$, $\left.\mathrm{CDCl}_{3}\right)(\mathrm{ppm}) \delta_{\mathrm{H}}: 2.50\left(\mathrm{~s}, 3 \mathrm{H}, \mathrm{C}_{6}-\mathrm{CH}_{3}\right), 3.29\left(\mathrm{~s}, 3 \mathrm{H}, \mathrm{C}_{7}-\mathrm{CH}_{3}\right), 7.71-$ $8.17\left(\mathrm{~m}, 6 \mathrm{H}, \mathrm{C}_{14}, \mathrm{C}_{2}, \mathrm{C}_{3}, \mathrm{C}_{8}, \mathrm{C}_{10}, \mathrm{C}_{11}-\mathrm{H}\right), 8.21\left(\mathrm{~d}, 1 \mathrm{H}, \mathrm{C}_{14}-\mathrm{H}, J=8.08 \mathrm{~Hz}\right)$, $9.39\left(\mathrm{~d}, 1 \mathrm{H}, \mathrm{C}_{4}-\mathrm{H}, J=8.50 \mathrm{~Hz}, J_{m}=1.50 \mathrm{~Hz}\right), 9.48\left(\mathrm{~d}, 1 \mathrm{H}, \mathrm{C}_{13}-\mathrm{H}, J=9.20\right.$ $\mathrm{Hz}) ;{ }^{13} \mathrm{C}$ NMR $\left(100 \mathrm{MHz}, \mathrm{CDCl}_{3}\right)(\mathrm{ppm}) \delta_{\mathrm{C}}: 23.89\left(\mathrm{C}_{7}-\mathrm{CH}_{3}\right), 28.63\left(\mathrm{C}_{6}-\right.$ $\left.\mathrm{CH}_{3}\right), 120.87\left(\mathrm{C}_{6 \mathrm{a}}\right), 122.54\left(\mathrm{C}_{13}\right), 123.36\left(\mathrm{C}_{7 \mathrm{a}}\right), 124.63\left(\mathrm{C}_{4}\right), 126.39\left(\mathrm{C}_{12 \mathrm{~b}}\right)$, $126.71\left(\mathrm{C}_{3}\right), 127.42\left(\mathrm{C}_{14}\right), 127.87\left(\mathrm{C}_{2}\right), 127.96\left(\mathrm{C}_{1}\right), 128.98\left(\mathrm{C}_{8}\right), 129.62$ $\left(\mathrm{C}_{9}\right), 130.71\left(\mathrm{C}_{4 \mathrm{a}}\right), 130.64\left(\mathrm{C}_{14 \mathrm{a}}\right), 131.37\left(\mathrm{C}_{11}\right), 132.49\left(\mathrm{C}_{10}\right), 133.57\left(\mathrm{C}_{11 \mathrm{a}}\right)$, $137.89\left(\mathrm{C}_{7}\right), 148.11\left(\mathrm{C}_{4 \mathrm{~b}}\right), 149.23\left(\mathrm{C}_{12 \mathrm{a}}\right), 158.65\left(\mathrm{C}_{6}\right) ; \mathrm{MS}(\mathrm{EI}) \mathrm{m} / \mathrm{z}(\%)$ $342\left(\mathrm{M}^{+}, 100\right), 344(\mathrm{M}+2,32)$; Anal. Calcd. for $\mathrm{C}_{22} \mathrm{H}_{15} \mathrm{ClN}_{2}(342)$ : C, 77.08; H, 4.41; N, 8.17; Found: C, 77.14; H, 4.38; N, 8.24\%.

6,9-Dimethyl-7-(naphthalen-1'-yl)benzo $[b]$ naphtho[ $[1,2-h][1,6]$ naphthyridine (15a): Yellow prisms; $\mathrm{mp}: 239-240^{\circ} \mathrm{C}$; Yield: (54\%). IR $\left(\mathrm{KBr}, \mathrm{cm}^{-1}\right) v_{\max }: 1598,1540(\mathrm{C}=\mathrm{N}) ;{ }^{1} \mathrm{H}$ NMR $\left(500 \mathrm{MHz}, \mathrm{CDCl}_{3}\right)(\mathrm{ppm})$ $\delta_{\mathrm{H}}: 2.32\left(\mathrm{~s}, 3 \mathrm{H}, \mathrm{C}_{6}-\mathrm{CH}_{3}\right), 3.16\left(\mathrm{~s}, 3 \mathrm{H}, \mathrm{C}_{9}-\mathrm{CH}_{3}\right), 7.39-8.09\left(\mathrm{~m}, 13 \mathrm{H}, \mathrm{C}_{1}\right.$, $\left.\mathrm{C}_{2}, \mathrm{C}_{3}, \mathrm{C}_{8}, \mathrm{C}_{10} \mathrm{C}_{11}, \mathrm{C}_{2}^{\prime}, \mathrm{C}_{3}^{\prime}, \mathrm{C}_{4}^{\prime}, \mathrm{C}_{5}^{\prime}, \mathrm{C}_{6}^{\prime}, \mathrm{C}_{7}^{\prime}, \mathrm{C}_{8}^{\prime},-\mathrm{H}\right), 8.19\left(\mathrm{~d}, 1 \mathrm{H}, \mathrm{C}_{14}-\mathrm{H}\right.$, $J=8.00 \mathrm{~Hz}), 9.33\left(\mathrm{~d}, 1 \mathrm{H}, \mathrm{C}_{4}-\mathrm{H}, J_{0}=8.50 \mathrm{~Hz}, J_{m}=2.50 \mathrm{~Hz}\right), 9.46(\mathrm{~d}, 1 \mathrm{H}$, $\left.\mathrm{C}_{13}-\mathrm{H}, J=9.00 \mathrm{~Hz}\right) ;{ }^{13} \mathrm{C}$ NMR $\left(125 \mathrm{MHz}, \mathrm{CDCl}_{3}\right)(\mathrm{ppm}) \delta_{\mathrm{C}}: 21.7\left(\mathrm{C}_{9}-\right.$ $\left.\mathrm{CH}_{3}\right), 29.7\left(\mathrm{C}_{6}-\mathrm{CH}_{3}\right), 119.57\left(\mathrm{C}_{2}{ }^{\prime}\right), 120.79\left(\mathrm{C}_{6 \mathrm{a}}\right), 122.67\left(\mathrm{C}_{13}\right), 123.20$ $\left(\mathrm{C}_{7 \mathrm{a}}\right), 124.86\left(\mathrm{C}_{4}\right), 125.89\left(\mathrm{C}_{12 \mathrm{~b}}\right), 126.68\left(\mathrm{C}_{3}\right), 127.02\left(\mathrm{C}_{14}\right), 127.31\left(\mathrm{C}_{2}\right)$, $127.56\left(\mathrm{C}_{1}\right), 127.77\left(\mathrm{C}_{8}^{\prime}\right), 127.91\left(\mathrm{C}_{3}^{\prime}\right) 128.22\left(\mathrm{C}_{4}^{\prime}\right), 128.39\left(\mathrm{C}_{5}^{\prime}\right), 128.51$ $\left(\mathrm{C}_{6}^{\prime}\right), 128.73\left(\mathrm{C}_{7}^{\prime}\right), 129.24\left(\mathrm{C}_{8}\right), 130.35\left(\mathrm{C}_{4 \mathrm{a}}\right), 130.88\left(\mathrm{C}_{14 \mathrm{a}}\right), 131.01\left(\mathrm{C}_{11}\right)$, $\left.\left.132.36\left(\mathrm{C}_{10}\right), 132.66\left(\mathrm{C}_{8 \mathrm{a}}{ }^{\prime}\right), 133.65\left(\mathrm{C}_{11 \mathrm{a}}\right)^{4}\right), 134.27\left(\mathrm{C}_{4 \mathrm{a}}\right)^{\prime}\right), 134.86\left(\mathrm{C}_{9}\right)$, $136.86\left(\mathrm{C}_{1}^{\prime}\right), 138.00\left(\mathrm{C}_{7}\right), 148.27\left(\mathrm{C}_{4 \mathrm{~b}}\right), 149.31\left(\mathrm{C}_{12 \mathrm{a}}\right), 158.73\left(\mathrm{C}_{6}\right)$; Anal. Calcd. for $\mathrm{C}_{32} \mathrm{H}_{22} \mathrm{~N}_{2}$ (434): C, 88.45; H, 5.10; N, 6.45; Found : C, 88.41, H 5.17, N 6.50\%.

9-Chloro-6-methyl- 7 - (naph thalen-1'-yl) benzo [ $b$ ] naphtho[1,2-h][1,6]naphthyridine (15b): Pale yellow solid; mp: 236$238^{\circ} \mathrm{C}$; Yield: $(52 \%)$. IR $\left(\mathrm{KBr}, \mathrm{cm}^{-1}\right) \mathrm{v}_{\max }: 1624(\mathrm{C}=\mathrm{N}), 1589,1543 ;{ }^{1} \mathrm{H}$ NMR $\left(500 \mathrm{MHz}, \mathrm{CDCl}_{3}\right)(\mathrm{ppm}) \delta_{\mathrm{H}}: 2.40\left(\mathrm{~s}, 3 \mathrm{H}, \mathrm{C}_{6}-\mathrm{CH}_{3}\right), 7.35-8.02(\mathrm{~m}$, 
$\left.12 \mathrm{H}, \mathrm{C}_{1}, \mathrm{C}_{2}, \mathrm{C}_{3}, \mathrm{C}_{8}, \mathrm{C}_{10}, \mathrm{C}_{11}, \mathrm{C}_{2}^{\prime}, \mathrm{C}_{3}{ }^{\prime}, \mathrm{C}_{5}{ }^{\prime}, \mathrm{C}_{4}^{\prime} \mathrm{C}_{6}^{\prime}, \mathrm{C}_{7}{ }^{\prime}, \mathrm{C}_{8}{ }^{\prime}-\mathrm{H}\right), 8.11(\mathrm{~d}, 1 \mathrm{H}$, $\left.\mathrm{C}_{14}-\mathrm{H}, J=8.00 \mathrm{~Hz}\right), 9.29\left(\mathrm{~d}, 1 \mathrm{H}, \mathrm{C}_{4}-\mathrm{H}, J_{0}=8.50 \mathrm{~Hz}, J_{m}=2.50 \mathrm{~Hz}\right), 9.41(\mathrm{~d}$, $\left.1 \mathrm{H}, \mathrm{C}_{13}-\mathrm{H}, J=9.00 \mathrm{~Hz}\right) ;{ }^{13} \mathrm{C}$ NMR $\left(125 \mathrm{MHz}, \mathrm{CDCl}_{3}\right)(\mathrm{ppm}) \delta_{\mathrm{C}}: 21.7$ $\left(\mathrm{C}_{9}-\mathrm{CH}_{3}\right), 29.7\left(\mathrm{C}_{6}-\mathrm{CH}_{3}\right), 119.64\left(\mathrm{C}_{2}^{\prime}\right), 120.87\left(\mathrm{C}_{62}\right), 122.91\left(\mathrm{C}_{13}\right), 122.46$ $\left(\mathrm{C}_{7 \mathrm{a}}\right), 124.77\left(\mathrm{C}_{4}\right), 126.01\left(\mathrm{C}_{12 \mathrm{~b}}\right), 126.84\left(\mathrm{C}_{3}\right), 127.09\left(\mathrm{C}_{14}\right), 127.41\left(\mathrm{C}_{2}\right)$, $127.60\left(\mathrm{C}_{1}\right), 127.76\left(\mathrm{C}_{8}^{\prime}\right), 127.89\left(\mathrm{C}_{3}^{\prime}\right), 128.05\left(\mathrm{C}_{8}\right), 128.25\left(\mathrm{C}_{4}^{\prime}\right), 128.41$ $\left(\mathrm{C}_{5}^{\prime}\right), 128.72\left(\mathrm{C}_{6}^{\prime}\right), 128.90\left(\mathrm{C}_{7}^{\prime}\right), 129.85\left(\mathrm{C}_{9}\right), 130.74\left(\mathrm{C}_{4 \mathrm{a}}\right), 130.91\left(\mathrm{C}_{14 \mathrm{a}}\right)$, $131.32\left(\mathrm{C}_{11}\right), 132.56\left(\mathrm{C}_{10}\right), 132.96\left(\mathrm{C}_{8 \mathrm{a}}{ }^{\prime}\right), 133.77\left(\mathrm{C}_{11 \mathrm{a}}\right), 135.98\left(\mathrm{C}_{1}^{\prime}\right)$, $137.69\left(\mathrm{C}_{7}\right), 147.55\left(\mathrm{C}_{4 \mathrm{~b}}\right), 149.12\left(\mathrm{C}_{12 \mathrm{a}}\right), 158.77\left(\mathrm{C}_{6}\right)$; Anal. Calcd. for $\mathrm{C}_{31} \mathrm{H}_{19} \mathrm{ClN}_{2}$ (404): C, 81.84; H, 4.21; N, 6.16; Found : C 81.78, H 4.27, N $6.22 \%$.

\section{General procedure for the synthesis of compound (16-18)}

2-methyl- $N$-phenylbenzo[h] quinolin-4-amine (12) (0.002 mol) and various hetero aromatic carboxylic acids $(0.0025 \mathrm{~mol})$ were added to polyphosphoric acid $\left(6 \mathrm{~g}\right.$ of $\mathrm{P}_{2} \mathrm{O}_{5}$ in $3 \mathrm{~mL}$ of $\left.\mathrm{H}_{3} \mathrm{PO}_{4}\right)$. The reaction time, temperature maintained and various acid used for the synthesis of respective product are mentioned in the Table 2. The reaction was monitored by using TLC. After the completion of the reaction, it was poured into ice water, neutralized with saturated sodium bicarbonate solution to remove excess of carboxylic acids, extracted with ethyl acetate, purified by column chromatography using silica gel and product eluted with petroleum ether:ethyl acetate (99:1) mixture to get 16-18 which was then recrystallised using methanol.

6,9-Dimethyl-7-(pyridin-3'-yl)benzo $[b]$ naphtho[ $[1,2-h][1,6]$ naphthyridine (16a): Yellow prisms; $\mathrm{mp}: 239-240^{\circ} \mathrm{C}$; Yield: (41\%). IR $\left(\mathrm{KBr}, \mathrm{cm}^{-1}\right) v_{\max }: 1610(\mathrm{C}=\mathrm{N}), 1588,1555 ;{ }^{1} \mathrm{H}$ NMR $\left(500 \mathrm{MHz}, \mathrm{CDCl}_{3}\right)$ $(\mathrm{ppm}) \delta_{\mathrm{H}}: 2.40\left(\mathrm{~s}, 3 \mathrm{H}, \mathrm{C}_{6}-\mathrm{CH}_{3}\right), 3.11\left(\mathrm{~s}, 3 \mathrm{H}, \mathrm{C}_{9}-\mathrm{CH}_{3}\right), 7.20\left(\mathrm{t}, 1 \mathrm{H}, \mathrm{C}_{5}^{\prime}-\mathrm{H}\right.$, $J=8.50 \mathrm{~Hz}, J=4.00 \mathrm{~Hz}) 7.45-7.71\left(\mathrm{~m}, 5 \mathrm{H}, \mathrm{C}_{2} \mathrm{C}_{3}, \mathrm{C}_{8}, \mathrm{C}_{10}, \mathrm{C}_{11}-\mathrm{H}\right), 7.81$ $\left(\mathrm{dd}, 1 \mathrm{H}, \mathrm{C}_{6}^{\prime}-\mathrm{H}, J=2.00 \mathrm{~Hz}, J=5.50 \mathrm{~Hz}\right), 7.87\left(\mathrm{dd}, 1 \mathrm{H}, \mathrm{C}_{4}^{\prime}-\mathrm{H}, J=2.00 \mathrm{~Hz}\right.$, $J=5.00 \mathrm{~Hz}), 7.95\left(\mathrm{~s}, 1 \mathrm{H}, \mathrm{C}_{2}^{\prime}-\mathrm{H}\right), 8.02\left(\mathrm{~d}, 1 \mathrm{H}, \mathrm{C}_{1}-\mathrm{H}, J=9.50 \mathrm{~Hz}\right), 8.10(\mathrm{~d}$, $\left.1 \mathrm{H}, \mathrm{C}_{14}-\mathrm{H}, J=7.50 \mathrm{~Hz}\right), 9.41\left(\mathrm{~d}, 1 \mathrm{H}, \mathrm{C}_{4}-\mathrm{H}, J=8.50 \mathrm{~Hz}, 9.59\left(\mathrm{~d}, 1 \mathrm{H}, \mathrm{C}_{13}-\mathrm{H}\right.\right.$, $J=8.00 \mathrm{~Hz}$ ); Anal. Calcd. for $\mathrm{C}_{27} \mathrm{H}_{19} \mathrm{~N}_{3}$ (385) C, 84.13; H, 4.97; N, 10.90; Found : C, 84.09, H 5.00, N 10.93\%.

9-Chloro-6-methyl-7-(pyridin-3'-yl)benzo[b]naphtho[ $[1,2-h]$ [1,6]naphthyridine (16b): Yellow prisms; mp: $233-235^{\circ} \mathrm{C}$; Yield: (41\%). IR $\left(\mathrm{KBr}, \mathrm{cm}^{-1}\right) v_{\max }: 1608(\mathrm{C}=\mathrm{N}), 1572,1550 ;{ }^{1} \mathrm{H}$ NMR $(500$ $\left.\mathrm{MHz}, \mathrm{CDCl}_{3}\right)(\mathrm{ppm}) \delta_{\mathrm{H}}: 2.44\left(\mathrm{~s}, 3 \mathrm{H}, \mathrm{C}_{6}-\mathrm{CH}_{3}\right), 7.23\left(\mathrm{t}, 1 \mathrm{H}, \mathrm{C}_{5}{ }^{\prime}-\mathrm{H} \mathrm{J}=8.50\right.$ $\mathrm{Hz}, J=4.00 \mathrm{~Hz})$ 7.43-7.75 (m, 5H, C $\left.\mathrm{C}_{3}, \mathrm{C}_{8}, \mathrm{C}_{10}, \mathrm{C}_{11}-\mathrm{H}\right), 7.85(\mathrm{dd}, 1 \mathrm{H}$, $\left.\mathrm{C}_{6}^{\prime}-\mathrm{H}, J=2.00 \mathrm{~Hz}, J=5.50 \mathrm{~Hz}\right), 7.86\left(\mathrm{dd}, 1 \mathrm{H}, \mathrm{C}_{4}^{\prime}-\mathrm{H}, J=2.00 \mathrm{~Hz}, J=5.00\right.$ $\mathrm{Hz}), 7.99\left(\mathrm{~s}, 1 \mathrm{H}, \mathrm{C}_{2}^{\prime}-\mathrm{H}\right), 8.06\left(\mathrm{~d}, 1 \mathrm{H}, \mathrm{C}_{1}-\mathrm{H}, J=9.50 \mathrm{~Hz}\right), 8.15(\mathrm{~d}, 1 \mathrm{H}$, $\left.\mathrm{C}_{14}-\mathrm{H}, J=7.50 \mathrm{~Hz}\right), 9.47\left(\mathrm{~d}, 1 \mathrm{H}, \mathrm{C}_{4}-\mathrm{H}, J=8.50 \mathrm{~Hz}\right), 9.61\left(\mathrm{~d}, 1 \mathrm{H}, \mathrm{C}_{13}-\mathrm{H}\right.$, $J=8.00 \mathrm{~Hz}$ ); Anal. Calcd. for $\mathrm{C}_{26} \mathrm{H}_{16} \mathrm{ClN}_{3}(405): \mathrm{C}, 76.94 ; \mathrm{H}, 3.97 ; \mathrm{N}$, 10.35; Found : C, $77.00 ; \mathrm{H}, 3.99 ; \mathrm{N}, 10.33 \%$.

6,9-dimethyl-7-(furan-2'-yl)benzo[b]naphtho $[1,2-h][1,6]$ naphthyridine (17a): Colourless prisms; $\mathrm{mp}$ : $243-245^{\circ} \mathrm{C}$; Yield: $(54 \%)$; IR $\left(\mathrm{KBr}, \mathrm{cm}^{-1}\right) v_{\max }: 1613(\mathrm{C}=\mathrm{N}), 1566,1511 ;{ }^{1} \mathrm{H}$ NMR $(500 \mathrm{MHz}$, $\left.\mathrm{CDCl}_{3}\right)(\mathrm{ppm}) \delta_{\mathrm{H}}: 2.55\left(\mathrm{~s}, 3 \mathrm{H}, \mathrm{C}_{6}-\mathrm{CH}_{3}\right), 3.21\left(\mathrm{~s}, 3 \mathrm{H}, \mathrm{C}_{9}-\mathrm{CH}_{3}\right), 6.70(\mathrm{t}$, $\left.1 \mathrm{H}, \mathrm{C}_{4}{ }^{\prime}-\mathrm{H}, J=4.50 \mathrm{~Hz}\right), 7.36\left(\mathrm{~d}, 1 \mathrm{H}, \mathrm{C}_{3}^{\prime}-\mathrm{H}, J=5.50 \mathrm{~Hz}\right), 7.51-8.05(\mathrm{~m}, 6 \mathrm{H}$, $\left.\mathrm{C}_{1}, \mathrm{C}_{2}, \mathrm{C}_{3}, \mathrm{C}_{10}, \mathrm{C}_{11}, \mathrm{C}_{5}^{\prime}-\mathrm{H}\right), 8.13\left(\mathrm{~d}, 1 \mathrm{H}, \mathrm{C}_{8}-\mathrm{H}, J=1.50 \mathrm{~Hz}\right), 8.44(\mathrm{~d}, 1 \mathrm{H}$, $\left.\mathrm{C}_{14}-\mathrm{H}, J=8.50 \mathrm{~Hz}\right), 9.37\left(\mathrm{~d}, 1 \mathrm{H}, \mathrm{C}_{4}-\mathrm{H}, J_{o}=8.50 \mathrm{~Hz}, J_{m}=2.00 \mathrm{~Hz}\right), 9.41(\mathrm{~d}$, $1 \mathrm{H}, \mathrm{C}_{13}-\mathrm{H}, J=9.50 \mathrm{~Hz}$ ); Anal. Calcd. for $\mathrm{C}_{26} \mathrm{H}_{18} \mathrm{~N}_{2} \mathrm{O}$ (374): C, 83.40; $\mathrm{H}$, 4.85 ; N, 7.48; Found : C, 83.44, H, 4.81, N, 7.51\%

9-Chloro-6-methyl-7-(furan-2'-yl)benzo $[b]$ naphtho $[1,2-h][1,6]$ naphthyridine (17b): Colourless prisms; mp: $235-237^{\circ} \mathrm{C}$; Yield: (54\%); IR $\left(\mathrm{KBr}, \mathrm{cm}^{-1}\right) v_{\max }: 1613(\mathrm{C}=\mathrm{N}), 1566,1511 ;{ }^{1} \mathrm{H}$ NMR $(500 \mathrm{MHz}$, $\left.\mathrm{CDCl}_{3}\right)(\mathrm{ppm}) \delta_{\mathrm{H}}: 2.49\left(\mathrm{~s}, 3 \mathrm{H}, \mathrm{C}_{6}-\mathrm{CH}_{3}\right), 6.72\left(\mathrm{t}, 1 \mathrm{H}, \mathrm{C}_{4}^{\prime}-\mathrm{H}, J=5.50 \mathrm{~Hz}\right)$, $7.40\left(\mathrm{~d}, 1 \mathrm{H}, \mathrm{C}_{3}^{\prime}-\mathrm{H}, J=5.00 \mathrm{~Hz}\right), 7.54-8.07\left(\mathrm{~m}, 6 \mathrm{H}, \mathrm{C}_{1}, \mathrm{C}_{2}, \mathrm{C}_{3}, \mathrm{C}_{10}, \mathrm{C}_{11}\right.$, $\left.\mathrm{C}_{5}{ }^{\prime}-\mathrm{H}\right), 8.17\left(\mathrm{~d}, 1 \mathrm{H}, \mathrm{C}_{8}-\mathrm{H}, J=2.00 \mathrm{~Hz}\right), 8.51\left(\mathrm{~d}, 1 \mathrm{H}, \mathrm{C}_{14}-\mathrm{H}, J=8.50 \mathrm{~Hz}\right)$, $9.40\left(\mathrm{~d}, 1 \mathrm{H}, \mathrm{C}_{4}-\mathrm{H}, J_{0}=8.50 \mathrm{~Hz}, J_{m}=2.00 \mathrm{~Hz}\right), 9.49\left(\mathrm{~d}, 1 \mathrm{H}, \mathrm{C}_{13}-\mathrm{H}, J=9.50\right.$
$\mathrm{Hz}$ ); Anal. Calcd. for $\mathrm{C}_{25} \mathrm{H}_{15} \mathrm{ClN}_{2} \mathrm{O}$ (394): C, 76.05; H, 3.83; N, 7.09; Found : C, 76.10, H, 3.79, N, 7.13\%

6,9-Dimethyl-7-(thiophen-2'-yl)benzo[b] naphtho[1,2-h][1,6] naphthyridine (18a): Colourless prisms; $\mathrm{mp}: 249-250^{\circ} \mathrm{C}$; Yield: $(54 \%)$; IR $\left(\mathrm{KBr}, \mathrm{cm}^{-1}\right) v_{\max }: 1613(\mathrm{C}=\mathrm{N}), 1566,1511 ; \mathrm{NMR}\left(\mathrm{CDCl}_{3}\right) \delta_{\mathrm{H}}: 2.53$ $\left(\mathrm{s}, 3 \mathrm{H}, \mathrm{C}_{6}-\mathrm{CH}_{3}\right), 3.20\left(\mathrm{~s}, 3 \mathrm{H}, \mathrm{C}_{9}-\mathrm{CH}_{3}\right), 6.71\left(\mathrm{t}, 1 \mathrm{H}, \mathrm{C}_{4}^{\prime}-\mathrm{H}, J=4.50 \mathrm{~Hz}\right)$, $7.39\left(\mathrm{~d}, 1 \mathrm{H}, \mathrm{C}_{3}^{\prime}-\mathrm{H}, J=5.00 \mathrm{~Hz}\right), 7.52-8.00\left(\mathrm{~m}, 6 \mathrm{H}, \mathrm{C}_{1}, \mathrm{C}_{2}, \mathrm{C}_{3}, \mathrm{C}_{10}, \mathrm{C}_{11}\right.$, $\left.\mathrm{C}_{5}^{\prime}-\mathrm{H}\right), 8.15\left(\mathrm{~d}, 1 \mathrm{H}, \mathrm{C}_{8}-\mathrm{H}, J=1.50 \mathrm{~Hz}\right), 8.49\left(\mathrm{~d}, 1 \mathrm{H}, \mathrm{C}_{14}-\mathrm{H}, J=8.00 \mathrm{~Hz}\right)$, $9.34\left(\mathrm{~d}, 1 \mathrm{H}, \mathrm{C}_{4}-\mathrm{H}, J_{0}=9.00 \mathrm{~Hz}, J_{m}=2.00 \mathrm{~Hz}\right), 9.50\left(\mathrm{~d}, 1 \mathrm{H}, \mathrm{C}_{13}-\mathrm{H}, J=9.00\right.$ $\mathrm{Hz}$ ); Anal. Calcd. for $\mathrm{C}_{26} \mathrm{H}_{18} \mathrm{~N}_{2} \mathrm{~S}(390)$ : C, 79.97; H, 4.65; N, 7.17; S, 8.21; Found : C, 79.94, H, 7.19, N, 8.24\%

9-Dhloro-6-methyl-7-(thiophen-2'-yl)benzo $[b]$ naphtho[1,2-h] [1,6]naphthyridine (18b): Colourless prisms; mp: $258-250^{\circ} \mathrm{C}$; Yield: (35\%); IR $\left(\mathrm{KBr}, \mathrm{cm}^{-1}\right) v_{\max }: 1603(\mathrm{C}=\mathrm{N}), 1576,1511 ; \mathrm{NMR}\left(\mathrm{CDCl}_{3}\right) \delta_{\mathrm{H}}$ : $2.49\left(\mathrm{~s}, 3 \mathrm{H}, \mathrm{C}_{6}-\mathrm{CH}_{3}\right), 6.72\left(\mathrm{t}, 1 \mathrm{H}, \mathrm{C}_{4}^{\prime}-\mathrm{H}, J=5.50 \mathrm{~Hz}\right), 7.40\left(\mathrm{~d}, 1 \mathrm{H}, \mathrm{C}_{3}^{\prime}-\mathrm{H}^{\mathrm{H}}\right.$, $J=5.00 \mathrm{~Hz}), 7.54-8.07\left(\mathrm{~m}, 5 \mathrm{H}, \mathrm{C}_{1}, \mathrm{C}_{2}, \mathrm{C}_{3}, \mathrm{C}_{10}, \mathrm{C}_{11}, \mathrm{C}_{5}^{\prime}-\mathrm{H}\right), 8.17(\mathrm{~d}, 1 \mathrm{H}$, $\left.\mathrm{C}_{8}-\mathrm{H}, J=2.00 \mathrm{~Hz}\right), 8.51\left(\mathrm{~d}, 1 \mathrm{H}, \mathrm{C}_{14}-\mathrm{H}, J=8.50 \mathrm{~Hz}\right), 9.40\left(\mathrm{~d}, 1 \mathrm{H}, \mathrm{C}_{4}-\mathrm{H}\right.$, $\left.J_{o}=8.50 \mathrm{~Hz}, J_{m}=2.00 \mathrm{~Hz}\right), 9.49\left(\mathrm{~d}, 1 \mathrm{H}, \mathrm{C}_{13}-\mathrm{H}, J=9.50 \mathrm{~Hz}\right)$; Anal. Calcd. for $\mathrm{C}_{25} \mathrm{H}_{15} \mathrm{ClN}_{2} \mathrm{~S}(410)$ : C, 73.07; H, 3.68; N, 6.82; S, 7.80; Found: C, 73.12, H, 3.72, N, 6.79; S, 7.77\%.

\section{In vitro cytotoxicity}

Experimental procedure for SRB assay: The cell lines (K562, MCF7, Hep-G2, and HeLa) were grown in RPMI 1640 medium containing $10 \%$ fetal bovine serum and $2 \mathrm{mM}$ L-glutamine. For present screening experiment, cells were inoculated into 96 well microtiter plates in $90 \mu \mathrm{L}$ at plating densities as shown in the study details above, depending on the doubling time of individual cell lines. After cell inoculation, the microtiter plates were incubated at $37^{\circ} \mathrm{C}, 5 \%$ $\mathrm{CO}_{2}, 95 \%$ air and $100 \%$ relative humidity for $24 \mathrm{~h}$ prior to addition of experimental drugs.

After $24 \mathrm{~h}$, one plate of each cell line was fixed in situ with TCA, to represent a measurement of the cell population for each cell line at the time of drug addition (Tz). Experimental drugs were solubilized in appropriate solvent at 400 -fold the desired final maximum test concentration and stored frozen prior to use. At the time of drug addition, an aliquot of frozen concentrate was thawed and diluted to 10 times the desired final maximum test concentration with complete medium containing test compound at a concentration of $10^{-3}$. Additional three, 10 -fold serial dilutions were made to provide a total of four drug concentrations plus control. Aliquots of $10 \mu \mathrm{l}$ of these different drug dilutions were added to the appropriate micro-titer wells already containing $90 \mu \mathrm{L}$ of medium, resulting in the required final drug concentrations.

Endpoint measurement: After compound addition, plates were incubated at standard conditions for 48 hours and assay was terminated by the addition of cold TCA. Cells were fixed in situ by the gentle addition of $50 \mu \mathrm{l}$ of cold $30 \%(\mathrm{w} / \mathrm{v})$ TCA (final concentration, $10 \%$ TCA) and incubated for 60 minutes at $4^{\circ} \mathrm{C}$. The supernatant was discarded; the plates were washed five times with tap water and air dried. Sulforhodamine B (SRB $)^{28,29}$ solution $(50 \mu \mathrm{l})$ at $0.4 \%(\mathrm{w} / \mathrm{v})$ in $1 \%$ acetic acid was added to each of the wells, and plates were incubated for 20 minutes at room temperature. After staining, unbound dye was recovered and the residual dye was removed by washing five times with $1 \%$ acetic acid. The plates were air dried. Bound stain was subsequently eluted with $10 \mathrm{mM}$ trizma base, and the absorbance was read on an Elisa plate reader at a wavelength of $540 \mathrm{~nm}$ with $690 \mathrm{~nm}$ reference wavelength. The results were expressed as the concentration at which there was $50 \%$ inhibition $\left(\mathrm{IC}_{50}\right)$. 


\section{Results and Discussion}

\section{Chemistry}

In the present work the synthesis of benzo[ $[h]$ naphtho[1,2-b][1,6] naphthyridine and benzo $[b]$ naphtho[ $[1,2-h][1,6]$ naphthyridine isomers was achieved from 4-chloro-2-methylquinolines (1a,b) and 4-chloro2-methylbenzo[h]quinolines (10) through the key intermediates 2,8-dimethyl- $N$-(1-naphthyl)quinoline-4-amine (3a,b) and 2-methyl$N$-o-tolylbenzo[ $h$ ]quinolin-4-amine (12a,b) respectively.

Recently we have reported the synthesis of compounds (3a,b$6 a, b)$ [27]. Now we report the preparation of novel hetero benzo[ $h]$ naphtho[1,2-b][1,6]naphthyridines $(7 \mathrm{a}, \mathrm{b}-9 \mathrm{a}, \mathrm{b})$ using the similar protocol which is depicted in Scheme 1.

Our aim is to introduce hetero ring in benzonaphthonaphthyridine analogues. In order to achieve this the potential intermediate (3a) was reacted with pyridine-3-carboxylic acid in the presence of PPA (Polyphosphoric acid) at $110^{\circ} \mathrm{C}$ for an hour. IR spectrum of compound 4a showed three sharp bands at $1634 \mathrm{~cm}^{-1}, 1598 \mathrm{~cm}^{-1}$, $1547 \mathrm{~cm}^{-1}$ confirms the presence of three $\mathrm{C}=\mathrm{N}$ groups. In its ${ }^{1} \mathrm{H}$ NMR spectrum two singlets at $\delta 2.36$ and 2.92 accounts for $\mathrm{C}_{4}$ and $\mathrm{C}_{8}-\mathrm{CH}_{3}$ respectively. All other aromatic protons resonated in the region at $\delta$ 7.15-9.68. Its ${ }^{13} \mathrm{C}$ NMR spectrum clearly showed the presence of 27 carbons. All the spectral and analytical details attest the structure of the compound as 2,6-dimethyl-7-(pyridin-3'-yl)benzo[ $h]$ naphtho[1,2- $b]$ $[1,6]$ naphthyridine $(7 a)$. The same reaction was carried out with other hetero substituted carboxylic acids like furan-2-carboxylic acid and thiophen-2-carboxylic acid, the reaction conditions (including time and temperature) is represented in Table 1 . The structures of all the compounds $(7 \mathrm{a}, \mathrm{b}-9 \mathrm{a}, \mathrm{b})$ were established by elemental and spectral analysis (Refer experimental section).

We envisaged the synthesis of benzo[b]naphtho[1,2- $h][1,6]$ naphthyridine isomer, the second isomer by treating 4-Chloro-2methylbenzo[h]quinoline [28] (10) with $p$-toluidine (11a) under neat condition at $190^{\circ} \mathrm{C}$ (Scheme 2). As expected compound 12a was obtained as a brown solid in $73 \%$ yield. In IR spectrum the absorption bands at $3371 \mathrm{~cm}^{-1}$ and $1628 \mathrm{~cm}^{-1}$ confirms the presence of $\mathrm{NH}$ and $\mathrm{C}=\mathrm{N}$ functional groups. Its ${ }^{1} \mathrm{H} \mathrm{NMR}$ spectrum showed the presence of methyl groups at $\delta 2.37$ and 2.70 for $\mathrm{C}_{4}{ }^{\prime}$ and $\mathrm{C}_{2}-\mathrm{CH}_{3}$. The peculiar $\mathrm{C}_{3}-\mathrm{H}$ appeared as a singlet at $\delta 6.63$. All the 10 aromatic protons appeared at $\delta$ 7.62-9.27 while two broad singlets each for one proton integration observed at $\delta 10.35$ and $\delta 13.56$ were assigned for $\mathrm{C}_{4}-\mathrm{NH}$ amino form and $\mathrm{N}_{1}-\mathrm{H}$ imino form respectively. The ratio of amino and imino form was found to be $1: 1$. Its ${ }^{13} \mathrm{C}$ NMR spectrum confirmed the presence of 21 carbons.

Finally the cyclisation of 2-methyl- $N$ - $p$-tolylbenzo[ $h]$ quinolin-4amine (12a) with benzoic acid in presence of polyphosphoric acid as catalyst afforded 6,9-dimethyl-7-phenylbenzo[ $b]$ naphtho[ $[1,2-h][1,6]$ naphthyridine (13a) (Scheme 3).

The IR Spectrum of 13a showed the absorption bands at $1624 \mathrm{~cm}^{-1}$ and $1561 \mathrm{~cm}^{-1}$ which were due to two $\mathrm{C}=\mathrm{N}$ functional groups. The ${ }^{1} \mathrm{H}$ NMR spectrum of 13a exhibited two singlets each at $\delta 2.38$ and 3.15 for $\mathrm{C}_{6}-\mathrm{CH}_{3}$ and $\mathrm{C}_{11}-\mathrm{CH}_{3}$ respectively. All the aromatic protons resonated at $\delta$ 7.35-8.25 except for two proton doublets which were very much deshielded at $\delta 9.39(J=8.00 \mathrm{~Hz})$ and $\delta 9.45(J=9.00 \mathrm{~Hz})$. With the help of 2D NMR studies (H,H-COSY, C,H-COSY, HSQC and HMBC) the deshielded proton at $\delta 9.39$ was assigned for $\mathrm{C}_{4}-\mathrm{H}$ while the proton at $\delta 9.45$ for $\mathrm{C}_{13}-\mathrm{H}$. Its ${ }^{13} \mathrm{C}$ NMR spectrum showed the appearance of 28 carbon signals and the mass spectrum identified the molecular ion peak at $m / z 384$. From its elemental analysis the molecular formula was deduced as $\mathrm{C}_{28} \mathrm{H}_{20} \mathrm{~N}_{2}$. All the above spectral and analytical details attest the structure of the compound as 6,9-dimethyl-7-phenylbenzo[b] naphtho[1,2-h][1,6]naphthyridine (13a). The generality of the reaction was tested with 4-chloroaniline (12b) in order to get the corresponding benzonaphthonaphthyridines (13b). The similar set of reaction was also extended to other carboxylic acids i.e., acetic acid and 1-naphthoic acid to get 6,7 -dimethylbenzo[ $b]$ naphtho[1,2-h][1,6]naphthyridines 14 and 6-methyl-7-(naphthalen-1-yl) benzo[b]naphtho[1,2-h][1,6] naphthyridine 15 respectively (Scheme 3 ). In all cases the $\mathrm{C}_{4}-\mathrm{H}$ and $\mathrm{C}_{13}-\mathrm{H}$ were deshielded. The reason for the two protons to get deshielded very much could be due to the interaction of these protons with the nitrogen atom at $5^{\text {th }}$ and $12^{\text {th }}$ position.

Further substrate scope of the reaction was examined using pyridine3-carboxylic acid, furan-2-carboxylic acid and thiophen-2-carboxylic acid the reaction conditions (including time and temperature) are represented in Table 2. The structures of all compounds were confirmed by elemental and spectral analysis (Refer experimental section).

\section{Biological activity}

Cytotoxicity: Various substituted benzo[h]naphtho[1,2-b][1,6] naphthyridine $(4 \mathrm{a}, \mathrm{b}-9 \mathrm{a}, \mathrm{b})$ and its isomeric benzo[b]naphtho[1,2- $h]$ $[1,6]$ naphthyridine derivatives $(13 \mathrm{a}, \mathrm{b}-18 \mathrm{a}, \mathrm{b})$ were synthesized from appropriate starting materials using two step synthetic steps which includes the condensation followed by subsequent cyclization with various aliphatic, aromatic and heteroaromatic carboxylic acids (Schemes 1 and 2). Positional isomers could show different biological response(s) during the in vitro assay, so we screened these isomeric compounds against four cancer cell lines namely, K562 (human leukaemia cancer cell line), MCF7 (human breast cancer cell line), Hep-G2 (human liver cancer cell line) and HeLa (human cervical cancer cell line) by SRB method $[29,30]$. The results for benzo[ $h]$ naphtho[1,2-b][1,6]naphthyridines $(4 \mathrm{a}, \mathrm{b}-9 \mathrm{a}, \mathrm{b})$ is presented in Table 3 and those for benzo[b]naphtho[1,2-h][1,6]naphthyridine derivatives $(13 a, b-18 a, b)$ are depicted in Table 4. Adriamycin (ADR), one of the

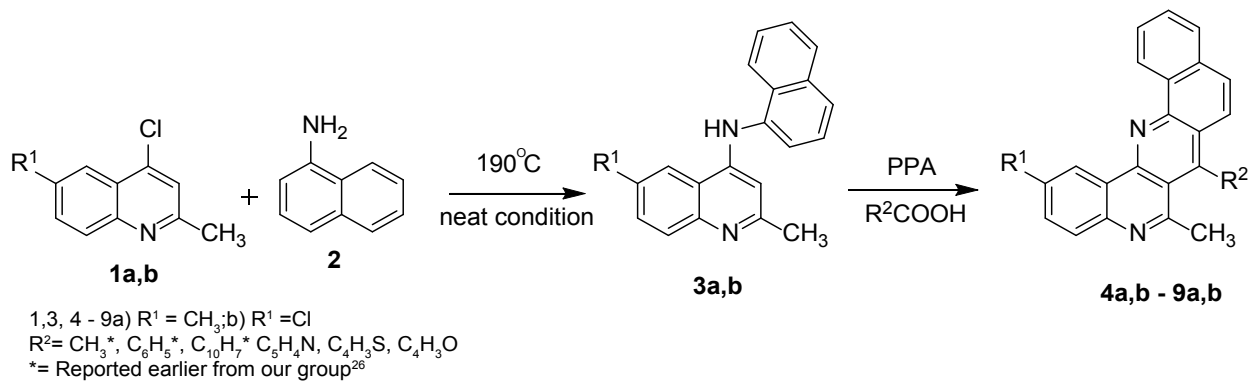

Scheme 1: Synthesis of benzo[h]naphtho[1,2-b][1,6]naphthyridines $4 a-b-9 a, b$. 
<smiles>[R]C1=c2c(C)nc3ccc([R])cc3c2=Nc2ccccc2C=C1</smiles>

$4 a, b-9 a, b$

$$
\begin{aligned}
4-9 a) R^{1} & =\mathrm{CH}_{3}, \\
\text { b) } R^{1} & =\mathrm{Cl}
\end{aligned}
$$

$\mathrm{R}^{2}=\mathrm{CH}_{3}{ }^{*}, \mathrm{C}_{6} \mathrm{H}_{5}{ }^{*}, \mathrm{C}_{10} \mathrm{H}_{7}{ }^{*}, \mathrm{C}_{5} \mathrm{H}_{4} \mathrm{~N}, \mathrm{C}_{4} \mathrm{H}_{3} \mathrm{O}, \mathrm{C}_{4} \mathrm{H}_{3} \mathrm{~S}$

\begin{tabular}{|c|c|c|c|c|}
\hline Compound & Acid & Product ${ }^{a}$ & $t(h)$ & $\mathrm{T}\left({ }^{\circ} \mathrm{C}\right)$ \\
\hline${ }^{*} 4 a, b$ & $\mathrm{COOH}$ & & 3 & 160 \\
\hline${ }^{*} 5 a, b$ & $\mathrm{CH}_{3} \mathrm{COOH}$ & & 3 & 160 \\
\hline${ }^{*} 6 a, b$ & & & 3 & 160 \\
\hline $7 a, b$ & & & 1 & 110 \\
\hline $8 a, b$ & & & 1 & 110 \\
\hline $9 a, b$ & $\mathrm{OH}$ & & 1 & 110 \\
\hline
\end{tabular}

${ }^{*}=$ Reported

a-The products were characterized by IR, NMR, mass and elemental analysis

Table 1: Reaction conditions for the preparation of benzo[h]naphtho[1,2-b][1,6]naphthyridines 7-9a,b. 


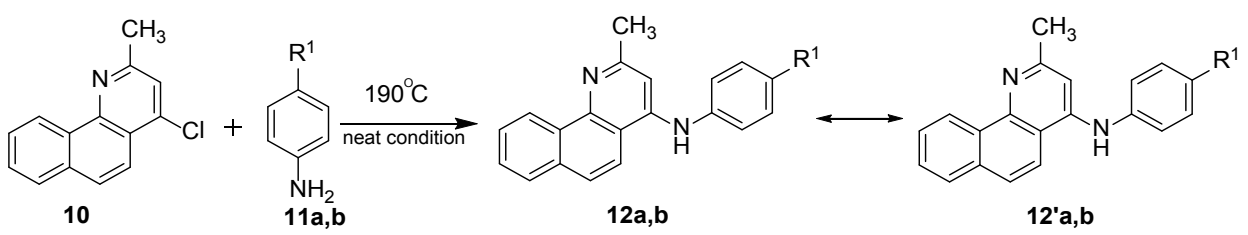

11, 12a) $\left.R^{1}=\mathrm{CH}_{3} ; b\right) R^{1}=\mathrm{Cl}$

Scheme 2: Synthesis of the intermediate compounds (12)

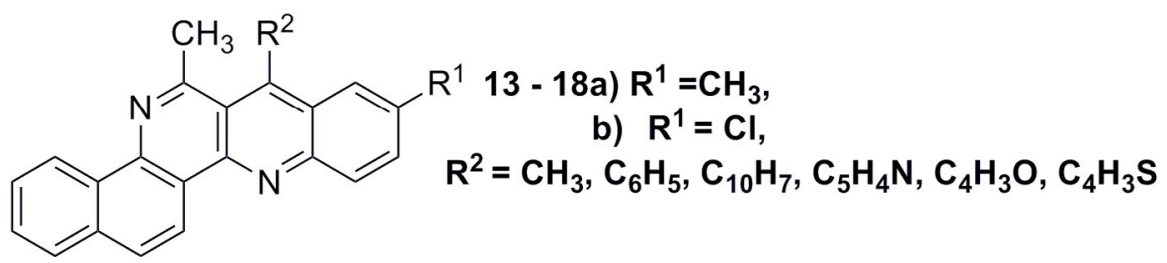

$13 a, b-18 a, b$

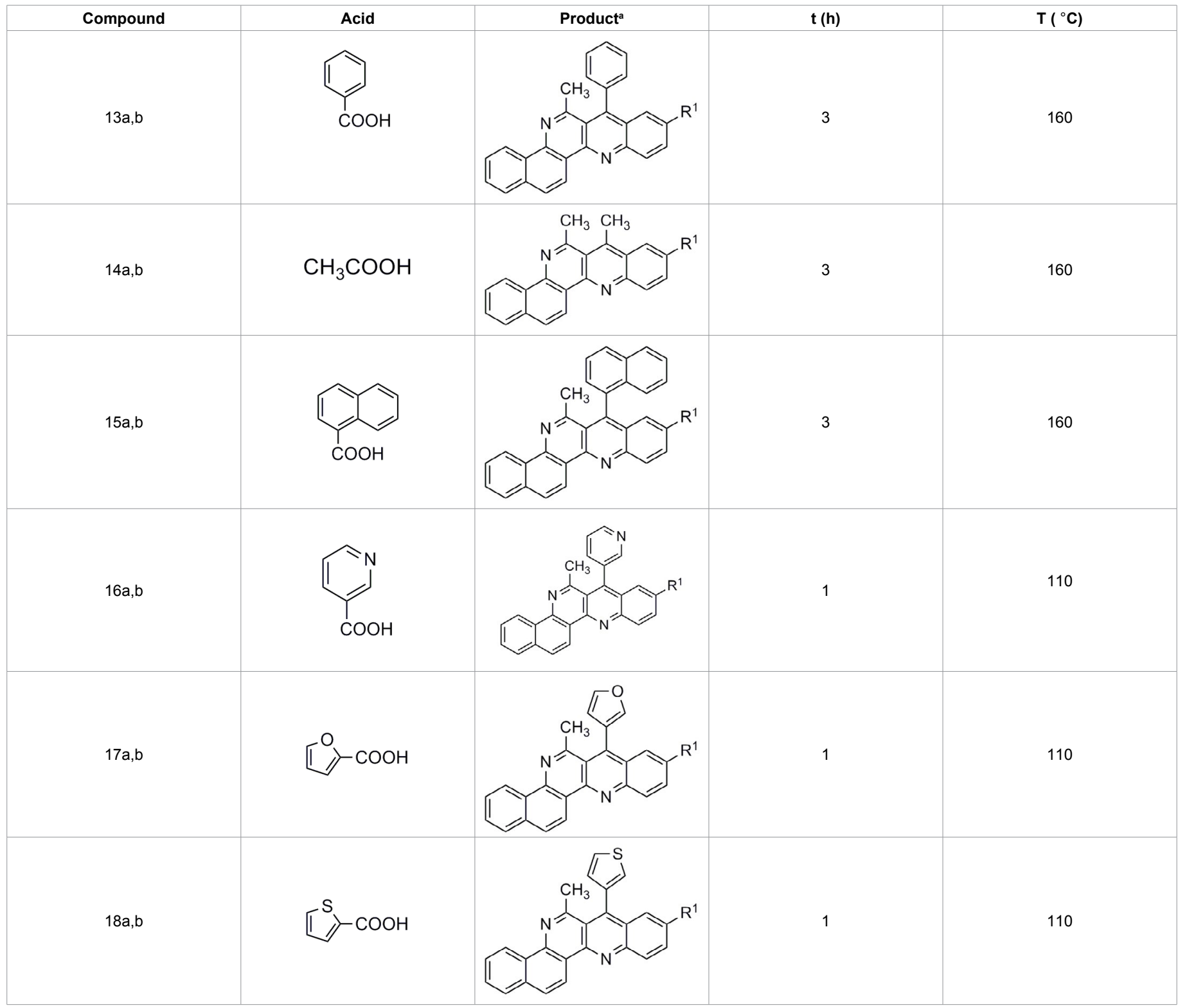

a-The products were characterized by IR, NMR, mass and elemental analysis

Table 2: Reaction conditions for the preparation of benzo[b]naphtho[1,2-h][1,6]naphthyridines 13a,b-18a,b. 
effective anticancer drug was taken as a reference to compare the cytotoxicity of the synthesized molecules. After careful examination of the results obtained, it is interesting to that both the isomers showed different activities in different cell lines as anticipated. Furthermore it also evident from the Tables 3 and 4 that in all the cases the chlorine derivative is more active than its methyl counterpart which clearly depicts the importance of electron withdrawing groups at $2^{\text {nd }}$ position of benzo $[h]$ naphtho[ $[1,2-b][1,6]$ naphthyridine and $9^{\text {th }}$ position of benzo[b]naphtho[ $[1,2-h][1,6]$ naphthyridine for its cytotoxicity. The results from in vitro activities of both the isomers were compared (Tables 3 and 4 ).
The precursors for the cyclization $3 \mathrm{a}$ (quinoline moiety and its $4^{\text {th }}$ position was substituted by naphthyl amine) and 12a (benzoquinoline core moiety and its $4^{\text {th }}$ position was substituted with aniline derivatives) showed good activity against all the four cell lines with $\mathrm{IC}_{50}$ range of 3.62-17.80 $\mu \mathrm{M}$ and 28.77-49.20 $\mu \mathrm{M}$ (Entry 1 in Tables 3 and 4 ) respectively. Very interestingly, incorporation of chlorine in 3a i.e., compound $3 \mathrm{~b}$ (Entry 2 in Table 3 ) showed very good activity with $\mathrm{IC}_{50}$ values of $1.05,11.65 \mu \mathrm{M}$ against HeLa and Hep-G2 cell lines which are 10 and 2 fold more active than adriyamycin $(11.52$ and $21.73 \mu \mathrm{M})$ whereas for K562 and MCF7 cell lines its IC $_{50}$ values are 7.23 and 6.63 $\mu \mathrm{M}$ respectively, which is comparable with positive control ADR (8.71

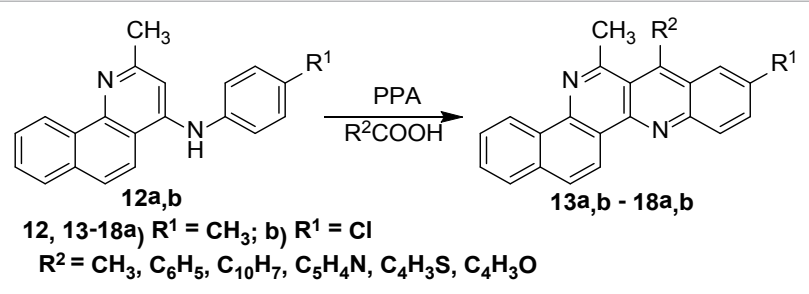

Scheme 3: Benzo[b]naphtho[1,2-h][1,6]naphthyridines13a,b - 18a,b

\begin{tabular}{|c|c|c|c|c|c|}
\hline Entry & Cpds & $\mathrm{K} 562^{\mathrm{a}}$ & MCF $^{\text {b }}$ & Hep-G2 ${ }^{c}$ & $\mathrm{HeLa}^{\mathrm{d}}$ \\
\hline 1 & $3 a$ & 17.20 & 9.17 & 17.80 & 3.62 \\
\hline 2 & $3 b$ & 7.23 & 6.63 & 11.65 & 1.05 \\
\hline 3 & $4 a$ & $>100$ & $>100$ & $>100$ & $>100$ \\
\hline 4 & $4 b$ & $>100$ & $>100$ & $>100$ & $>100$ \\
\hline 5 & $5 a$ & $>100$ & $>100$ & $>100$ & $>100$ \\
\hline 6 & $5 b$ & $>100$ & 95.48 & 90.68 & $>100$ \\
\hline 7 & $6 a$ & 74.94 & 77.29 & $>100$ & $>100$ \\
\hline 8 & $6 b$ & 66.42 & 70.56 & 68.23 & $>100$ \\
\hline 9 & $7 a$ & 49.01 & 18.06 & 29.09 & 41.25 \\
\hline 10 & $7 b$ & 42.18 & 12.33 & 24.66 & 32.11 \\
\hline 11 & $8 a$ & 29.66 & 14.22 & 14.41 & 20.53 \\
\hline 12 & $8 b$ & 21.86 & 9.03 & 10.76 & 13.82 \\
\hline 13 & $9 a$ & 15.85 & 11.44 & 7.93 & 6.21 \\
\hline 14 & $9 b$ & 7.01 & 5.93 & 6.86 & 1.41 \\
\hline 15 & ADR & 8.71 & 9.93 & 21.73 & 11.52 \\
\hline
\end{tabular}

a K562 (human leukaemia cancer cell line), ${ }^{\mathrm{b}}$ MCF7 (human breast cancer cell line),

${ }^{\mathrm{c}}$ Hep-G2 (human liver cancer cell line), d HeLa (human cervical cancer cell line)

Table 3: Cytotoxicity of compounds 3-9 $\left(\mathrm{IC}_{50}\right.$ in $\left.\mu \mathrm{M}\right)$.

\begin{tabular}{|c|c|c|c|c|c|}
\hline Entry & Cpds & K562 ${ }^{a}$ & MCF7 $^{\text {b }}$ & Hep-G2 ${ }^{c}$ & HeLa $^{d}$ \\
\hline 1 & $12 a$ & 49.20 & 28.77 & 30.33 & 37.3 \\
\hline 2 & $12 b$ & 36.81 & 25.18 & 24.17 & 28.77 \\
\hline 3 & $13 a$ & $>100$ & $>100$ & $>100$ & $>100$ \\
\hline 4 & $13 b$ & $>100$ & $>100$ & $>100$ & $>100$ \\
\hline 5 & $14 a$ & $>100$ & $>100$ & $>100$ & $>100$ \\
\hline 6 & $14 b$ & $>100$ & $>100$ & $>100$ & $>100$ \\
\hline 7 & $15 a$ & 72.22 & 58.45 & 67.05 & NA \\
\hline 8 & $15 b$ & 53.55 & 50.54 & 50.47 & NA \\
\hline 9 & $16 a$ & 52.52 & 45.12 & 40.54 & 40.11 \\
\hline 10 & $16 b$ & 48.24 & 43.19 & 35.54 & 36.42 \\
\hline 11 & $17 a$ & 40.09 & 35.37 & 27.77 & 24.22 \\
\hline 12 & $17 b$ & 37.88 & 34.19 & 22.22 & 20.77 \\
\hline 13 & $18 a$ & 33.11 & 18.09 & 21.56 & 17.87 \\
\hline 14 & $18 b$ & 30.8 & 13.68 & 17.85 & 14.91 \\
\hline 15 & ADR & 8.71 & 9.93 & 21.73 & 11.52 \\
\hline
\end{tabular}

a K562 (human leukaemia cancer cell line), ${ }^{\mathrm{b}}$ MCF7 (human breast cancer cell line),

${ }^{\mathrm{c}}$ Hep-G2 (human liver cancer cell line), ${ }^{\mathrm{d}} \mathbf{H e L a}$ (human cervical cancer cell line)

Table 4: Cytotoxicity of compounds $12-18\left(\mathrm{IC}_{50}\right.$ in $\left.\mu \mathrm{M}\right)$. 
and $9.93 \mu \mathrm{M})$. Similarly, $12 \mathrm{~b}$ (chlorine derivative) is more active than its methyl derivative compound 12a, (Entries 1 and 2 in Table 4). The overall comparision of intermediates depicts that $3 \mathrm{~b}$ is more potential than $12 \mathrm{~b}$ which is pictorially represented in Figure 2.

Substitution of methyl, phenyl substituents at $7^{\text {th }}$ position (Entries 3-6 in Tables 3 and 4) did not give beneficial results in both the isomers (4a,b-5a,b and 13a,b-14a,b), whereas increasing the hydrophobicity from phenyl to naphthyl, increases the activity marginally in both isomers (Entries 7, 8 in Tables 3 and 4).

As evident from the Tables 3 and 4 (Entries 9-14), a clear trend was found in cytotoxicity when the substitution at $7^{\text {th }}$ position containing pyridine moiety $(7 \mathrm{a}, \mathrm{b}$ and $16 \mathrm{a}, \mathrm{b})$ was replaced by furan ring $(8 \mathrm{a}, \mathrm{b}$ and $17 \mathrm{a}, \mathrm{b})$ which in turn is replaced by thiophene moiety (9a,b and 18a,b). Compound 7 a derived from pyridine carboxylic acid showed moderate anticancer activity $\left(\mathrm{IC}_{50}\right.$ value range 18.06-49.01 $\mu \mathrm{M}$ ) and the activity further increases marginally by a chlorine substitution at $2^{\text {nd }}$ position (7b). Compound $7 \mathrm{~b}$ showed better activity against MCF7 with $\mathrm{IC}_{50}$ value of $12.33 \mu \mathrm{M}$, moderate activity against Hep- $\mathrm{G}_{2}$ and HeLa cell lines with $\mathrm{IC}_{50}$ values 24.66 and $32.11 \mu \mathrm{M}$ respectively, displayed least active against $\mathrm{K} 562$ with $\mathrm{IC}_{50}$ value of $42.18 \mu \mathrm{M}$. In case of its isomeric compounds i.e., compound (16a,b) showed moderate activity towards all the four cell lines with the $\mathrm{IC}_{50}$ values in the range of 35.54 to 52.52 $\mu \mathrm{M}$.

Interestingly when pyridine carboxylic acid is replaced by furan and thiophene carboxylic acids the activity shoots up steeply. For compounds $8 \mathrm{a}, \mathrm{b}$ similar pattern was observed that chloro substituted compound $8 \mathrm{~b}$ was more active than methyl substituted compound $8 \mathrm{a}$ as mentioned earlier. Compound $8 \mathrm{~b}$ displayed stronger cytotoxicity against MCF7 and Hep-G2 cell lines with $\mathrm{IC}_{50}$ values 9.03 and 10.76 $\mu \mathrm{M}$. It showed almost equipotent activity with the control against MCF7 and tenfold more active against Hep-G2 cancer cell. For K562 and HeLa cancer lines $8 \mathrm{~b}$ showed moderate activity. Its isomeric compound $17 \mathrm{~b}$ showed moderate activity against all the four cell lines. To our delight, thiophene substituted isomers, (9a,b and 18a,b) showed the best anti-proliferative activity among the compounds screened in this study. Among them $9 \mathrm{~b}$ is the most outstanding compound which showed highest range of activity in this series with $\mathrm{IC}_{50}$ values 7.01, 5.93, 6.86 and $1.41 \mu \mathrm{M}$ against K562, MCF7, Hep-G2 and HeLa cell lines which were 15 fold active than standard against Hep-G2 and 10 fold more active against HeLa cancer cell lines. Its isomeric compound $18 \mathrm{~b}$ also showed excellent activity against Hep-G2 cancer cell line with an $\mathrm{IC}_{50}$ value 17.85 which was four fold active when compared to standard and showed significant activity against MCF7 and HeLa cell lines with $\mathrm{IC}_{50} 13.68$ and 14.91 and least activity against K562 cell line. This observation strongly support that the presence of thiophene moiety $[31,32]$ enhance the cytotoxic activity. By comparing the two isomers, various substituted benzo[ $h]$ naphtho[ $[1,2-b][1,6]$ naphthyridine series (4-9) were more active than its isomeric various substituted benzo[b] naphtho[1,2-h][1,6] naphthyridines (13-18) and is pictorially depicted in Figure 3.

From the present study, it is clear that substitution at $7^{\text {th }}$ position of benzo[h]naphtho[1,2-b][1,6] naphthyridine and its isomeric benzo $[b]$ naphtho $[1,2-h][1,6]$ naphthyridine derivatives is one of the potential sites to derivatize and could be instrumental in achieving good cytotoxicity. In this study, hetero substituted compounds showed excellent activity than aliphatic and aromatic substituted compounds. Among the hetero substituted compounds, compound containing thiophene moiety displayed highest activity than furan and pyridine substituted benzo[ $h]$ naphtho[ $[1,2-b][1,6]$ naphthyridines and benzo[ $b]$ naphtho[1,2-h][1,6]naphthyridines (Figure 4). In general electron withdrawing [33] chloro group enhances the anticancer activity of all the tested compounds when compared to electron donating group methyl group.

\section{Conclusion}

In conclusion, We have synthesized 7-substituted benzo[h] naphtho[1,2-b][1,6]naphthyridines $4-9$ and its isomeric benzo[b] naphtho[1,2-h][1,6]naphthyridines 13-18 where the substituents hold alkyl, aryl and hetero moieties and successful screened for anticancer against four cancer cell lines (K562, MCF7, Hep-G2 and HeLa). The structure-activity relationship study revealed that benzo[h]naphtho[1,2-b][1,6]naphthyridine 4-9 series showed good cytotoxicity compared to its isomeric benzo[ $b]$ naphtho[ $[1,2-h][1,6]$ naphthyridine derivatives $13-18$. The intermediate compound $3 b$ bearing chloro group and the compound 14 holds chloro group and thiophene moiety in naphthyridine nucleus turns out to be the best candidate in the series screened. All the above results indicates that these new compounds represent useful templates for development of new anticancer agents.

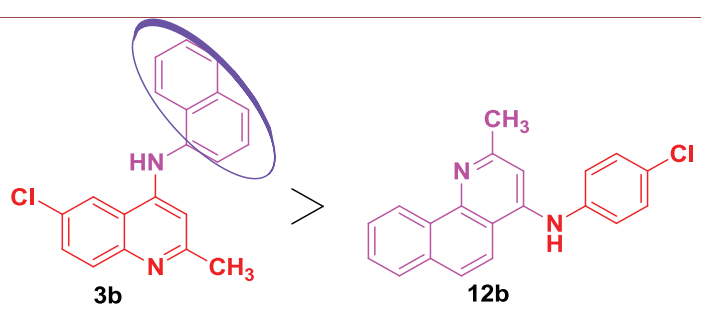

Figure 2: Comparison of cytotoxic activity of the intermediates $3 b$ and $12 b$.

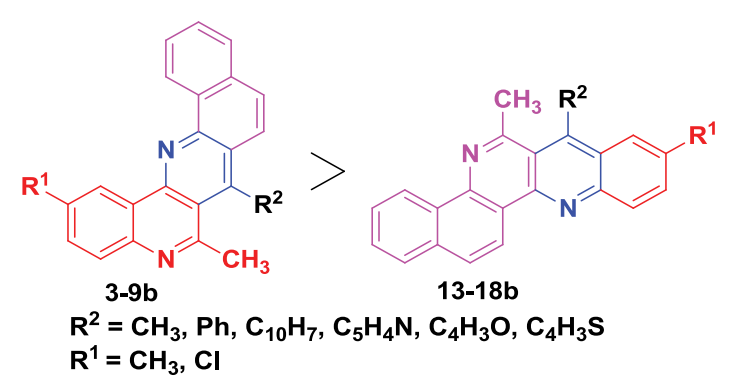

Figure 3: Benzo[h]naphtho[1,2-b][1,6] naphthyridine showing better cytotoxicity than its isomer benzo[b]naphtho[1,2- $h][1,6]$ naphthyridine.

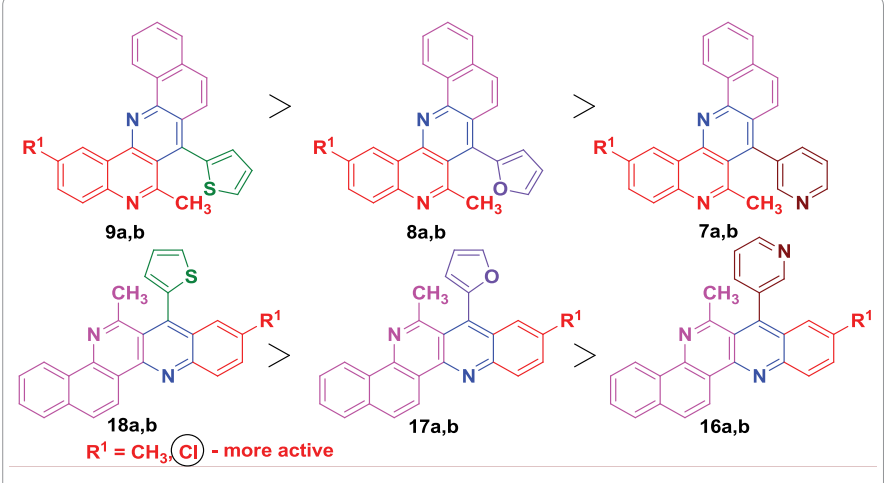

Figure 4: Influence of hetero substituents on cytotoxicity. 
Citation: Prabha K, Prasad KJR (2016) Synthesis and Cytotoxic Distinction of Benzo[h]naphtho[1,2-b][1,6] Naphthyridine and its Isomeric Benzo[b] naphtho[1,2-h][1,6] Naphthyridines. Med chem 6: 062-071. doi:10.4172/2161-0444.1000326

\section{Acknowledgements}

This work was supported by the Council of Scientific and Industrial Research, New Delhi for the award of Senior Research fellow (SRF) to K. Prabha is gratefully acknowledged. Dr. K. J. Rajendra Prasad was greatly acknowledged to UGC-BSR one time research grant. We thank Indian Institute of Technology Madras, Chennai and Indian Institute of Science, Bangalore for NMR and Indian Institute of Chemical Technology, Hyderabad for Mass spectral data. We acknowledge Tata cancer research centre, Mumbai for evaluating cytotoxicity.

\section{References}

1. Ljunggren B, Wirestrand LE (1988) Phototoxic properties of quinine and quinidine: two quinoline methanol isomers. Photodermatol 5: 133-138.

2. Zhou W, Zhang X, Xiao L, Ding J, Liu QH, et al. (2011) Semi-synthesis and antitumor activity of 6-isomers of 5, 8-O-dimethyl acylshikonin derivatives. Eur J Med Chem 46: 3420-3427.

3. Zhou W, Peng Y, Li SS (2010) Semi-synthesis and anti-tumor activity of 5,8-O-dimethyl acylshikonin derivatives. Eur J Med Chem 45: 6005-6011.

4. Zhao YL, Chen YL, Tzeng CC, Chen IL, Wang TC, et al. (2005) Synthesis and cytotoxic evaluation of certain 4-(phenylamino)furo[2,3-b]quinoline and 2-(furan-2yl)-4-(phenylamino)quinoline derivatives. Chem Biodivers 2: 205-214.

5. Verimer T, Long JP, Rusterholz DR, Flynn JR, Cannon JG, et al. (1980) Dopaminergic activity of cis-trans isomers of benzhydro[f]quinoline analogs. Eur J Pharmacol 64: 271-277.

6. Sanjay KS, Amrita J, Shiv KA, Rama M, Anand CB (2007) Synthesis and structure-activity relationships of potent antitumor active quinoline and naphthyridine derivatives. Anti Canc Agents Med chem 7: 685-709.

7. Jain PP, Degani MS, Raju A, Ray M, Rajan MG (2013) Rational drug design based synthesis of novel arylquinolines as anti-tuberculosis agents. Bioorg Med Chem Lett 23: 6097-6105.

8. Upadhayaya RS, Kulkarni GM, Vasireddy NR, Vandavasi JK, Dixit SS, et al. (2009) Design, synthesis and biological evaluation of novel triazole, urea and thiourea derivatives of quinoline against Mycobacterium tuberculosis. Bioorg Med Chem 17: 4681-4692.

9. Yeh LC, Chao JH, Zun YH, Chih HT, Feng SC, et al. (2006) Synthesis and antiproliferative evaluation of certain 4-anilino-8-methoxy-2-phenylquinoline and 4-anilino-8-hydroxy-2-phenylquinoline derivatives. Bioorg Med Chem 14: 3098-3105.

10. Eun JK, Mohammed IE, Chang HO, So HL, Taebo S, et al. (2013) New diarylamides and diarylureas possessing 8-amino(acetamido)quinoline scaffold: Synthesis, anti proliferative activities against melanoma cell lines, kinase inhibition, and in silico studies. Eur J Med Chem 70: 10-21.

11. Rossiter S, Péron JM, Whitfield PJ, Jones K (2005) Synthesis and anthelmintic properties of arylquinolines with activity against drug-resistant nematodes. Bioorg Med Chem Lett 15: 4806-4808.

12. Kidwai M, Bhushan KR, Sapra P, Saxena RK, Gupta R (2000) Aluminasupported synthesis of antibacterial quinolines using microwaves. Bioorg Med Chem 8: 69-72.

13. Fernanda da CS, Paula A, Helena CC, Paixao ICPP, Claudio CCS, et al. (2009) Synthesis, antiviral activity and molecular modeling of oxo quinoline derivatives. Bioorg Med Chem 17: 5476-5481.

14. Yanong DW, Karen M, Diane HB, Fei Y, Biqi WM, et al. (2000) Inhibitors of Src tyrosine kinase: The preparation and structure-activity relationship of 4-anilino-3- cyanoquinolines and 4-anilinoquinazolines. Bioorg Med Chem Lett 10: $2477-2480$

15. Nuran K, Busra Y, Ayca A, Zeynep I, Fatih SB, et al. (2013) Synthesis, antibacterial and antioxidant activities of new 1-alkyl-4-(1-alkyl-4-oxo-,4dihydroquinolin-2-yl)pyridinium bromides. Eur J Med Chem 69: 348-355.
16. Maria IF, Concepcion P, Gema CG, Santiago C, Manuela GL, et al. (2010) Novel tacrine-8-hydroxyquinoline hybrids as multifunctional agents for the treatment of alzheimer's disease, with neuroprotective, cholinergic, antioxidant, and copper-complexing properties. J Med Chem 53: 4927-4937.

17. Ruchelman AL, Singh SK, Ray A, Wu XH, Yang JM, et al. (2003) 5H-Dibenzo[c,h],6naphthyridin-6-ones: novel topoisomerase I-targeting anticancer agents with potent cytotoxic activity. Bioorg Med Chem 11: 2061-2073.

18. Yiwei L, Jun L, Tony S, Essa H, Michael AR, et al. (2009) Allosteric inhibitors of Akt1 and Akt2: Discovery of [,2,4] triazolo[3,4-f][,6]naphthyridines with potent and balanced activity. Bioorg Med Chem Lett 19: 834-836.

19. Zhuang L, Wai JS, Embrey MW, Fisher TE, Egbertson MS, et al. (2003) Design and synthesis of 8-hydroxy-[,6]naphthyridines as novel inhibitors of HIV-1 integrase in vitro and in infected cells. J Med Chem 46: 453-456.

20. Brian AJ, Jason GW, Scott HA, James BT, Edward PG, et al. (2009) The use of oxadiazole and triazole substituted naphthyridines as HIV-1integrase inhibitors. Part 1: Establishing the pharmacophore. Bioorg Med Chem Lett 19: 1802-1806.

21. Yong $W$, Zhong-Liang $X$, Jing $A$, Xia $P$, Jian-Ping L, et al. (2013) Investigation on the ,6-naphthyridine motif: discovery and SAR study of $1 \mathrm{H}$-imidazo[4,5-h][,6] naphthyridin-2(3H)-one-based c-Met kinase inhibitors. Org Biomol Chem 11: 1545-1562.

22. Rudys S, Rios-Luci C, Perez-Roth E, Cikotiene I, Padron JM (2010) Antiproliferative activity of novel benzo[b][,6]naphthyridines in human solid tumor cell lines. Bioorg Med Chem Lett 20: 1504-1506.

23. Insuasty B, Becerra D, Quiroga J, Abonia R, Nogueras M, et al. (2013) Microwave-assisted synthesis of pyrimido[4,5-b][,6]naphthyridin-4(3H)-ones with potential antitumor activity. Eur J Med Chem 60: 1-9.

24. Deady LW, Rodemann T, Zhuang L, Baguley BC, Denny WA (2003) Synthesis and cytotoxic activity of carboxamide derivatives of benzo[b][,6]naphthyridines. J Med Chem 46: 1049-1054.

25. Austin NE, Hadley MS, Harling JD, Harrington FP, Macdonald GJ, et al. (2003) The design of 8,8-dimethyl[,6]naphthyridines as potential anticonvulsant agents. Bioorg Med Chem Lett 13: 1627-1629.

26. Manera C, Cascio MG, Benetti V, AllarÃ M, Tuccinardi T, et al. (2007) New ,8-naphthyridine and quinoline derivatives as CB2 selective agonists. Bioorg Med Chem Lett 17: 6505-6510.

27. Prabha K, Rajendra Prasad KJ (2012) Synthesis of alkyl and aryl substituted benzo[h]naphtho[,2-b] [,6] naphthyridines. Syn Comm 42: 2277-2289.

28. Prabha K, Rajendra Prasad KJ (2013) Dinaphthonaphthyridines - a class of novel molecules with potent antioxidant and anticancer activity. Med Chem Comm 4: 340-346.

29. Vichai V, Kirtikara K (2006) Sulforhodamine B colorimetric assay for cytotoxicity screening. Nat Protoc 1: 1112-1116.

30. $\mathrm{NCI}$ Protocols. In vitro methodology.

31. Starcevic K, Krali M, Piantanida I, Suman L, Pavelic K, et al. (2006) Synthesis, photochemical synthesis, DNA binding and antitumor evaluation of novel cyanoand amidino-substituted derivatives of naphtha-furans, naphtho-thiophenes, thieno-benzofurans, benzo-dithiophenes and their acyclic precursors. Eur $J$ Med Chem 41: 925-939.

32. Wang YD, Johnson S, Powell D, McGinnis JP, Miranda M, et al. (2005) Inhibition of tumor cell proliferation by thieno[2,3-d]pyrimidin-4(1H)-one-based analogs. Bioorg Med Chem Lett 15: 3763-3766.

33. Bang SC, Kim Y, Yun MY, Ahn BZ (2004) 5-Arylidene-2(5H)-furanone derivatives: synthesis and structure-activity relationship for cytotoxicity. Arch Pharm Res 27: 485-494. 